\title{
The flanker compatibility effect as a function of visual angle, attentional focus, visual transients, and perceptual load: A search for boundary conditions
}

\author{
JEFF MILLER \\ University of California, San Diego, California
}

\begin{abstract}
When subjects must respond to a relevant center letter and ignore irrelevant flanking letters, the identities of the flankers produce a response compatibility effect, indicating that they are processed semantically at least to some extent. Because this effect decreases as the separation between target and flankers increases, the effect appears to result from imperfect early selection (attenuation). In the present experiments, several features of the focused attention paradigm were examined, in order to determine whether they might produce the flanker compatibility effect by interfering with the operation of an early selective mechanism. Specifically, the effect might be produced because the paradigm requires subjects to (1) attend exclusively to stimuli within a very small visual angle, (2) maintain a long-term attentional focus on a constant display location, (3) focus attention on an empty display location, (4) exclude onset-transient flankers from semantic processing, or (5) ignore some of the few stimuli in an impoverished visual field. The results indicate that none of these task features is required for semantic processing of unattended stimuli to occur. In fact, visual angle is the only one of the task features that clearly has a strong influence on the size of the flanker compatibility effect. The invariance of the flanker compatibility effect across these conditions suggests that the mechanism for early selection rarely, if ever, completely excludes unattended stimuli from semantic analysis. In addition, it shows that selective mechanisms are relatively insensitive to several factors that might be expected to influence them, thereby supporting the view that spatial separation has a special status for visual selective attention.
\end{abstract}

The way in which unattended visual stimuli are processed has long been a point of contention in experimental psychology. Despite dozens of experimental and theoretical analyses of the subject, basic disagreements about the mechanisms and locus of attentional selection remain (Allport, Tipper, \& Chmiel, 1985; Broadbent, 1982; Duncan, 1980; C. W. Eriksen \& St. James, 1986; Johnston \& Dark, 1986; Kahneman \& Treisman, 1984; Neisser, 1979).

Traditionally, two extreme theoretical positions have been distinguished. According to the late selection view (see, e.g., Deutsch \& Deutsch, 1963), all stimuli are automatically processed until semantic identification occurs, at which point attended stimuli are selected for the control of behavior. According to the early selection view (see, e.g., Broadbent, 1958, 1982), stimuli are selected

This research was supported by Grant PHS-MH40733 from the National Institute of Mental Health. I would like to thank Lisa Arcinega, Mark Carrier, Grace Fang, David Krajicek, Albano Lopes, and Tony Richardson for assistance in testing the subjects, and Charles Eriksen, Patricia Haden, Steven Hillyard, Jim Hoffman, Harold Pashler, Steve Yantis, and two anonymous reviewers for helpful comments on earlier drafts of the manuscript. A version of this paper was prepared while the author was a visiting professor at the Department of Psychology of the University of Amsterdam. Correspondence concerning this article should be addressed to Jeff Miller, Department of Psychology, C-009, University of California, La Jolla, CA 92093. prior to semantic analysis, on the basis of their physical features. Attended stimuli are processed semantically, but unattended stimuli are blocked from such analysis. ${ }^{1}$

A survey of the literature reveals very good reasons for the disagreements (see, e.g., Johnston \& Dark, 1986; Lambert, 1985). Under some circumstances, behavioral evidence has indicated that unattended visual stimuli have been identified; but under other circumstances, the evidence has indicated that they have not. In several experiments, for example, subjects watched a videotape of two optically superimposed episodes, attending only to one of the episodes (see, e.g., Becklen \& Cervone, 1983; Littman \& Becklen, 1976; Neisser \& Becklen, 1975). The subjects could easily attend to one episode selectively, and they noticed little or nothing that occurred in the unattended episode. On the basis of these and other findings, Neisser (1979) argued that there can be little or no processing of unattended visual stimuli. Another compelling example of early selection was provided by Johnston and Dark (1982), who found that semantic priming effects were produced only by attended stimuli, not by unattended ones.

On the other hand, it is clear that unattended stimuli sometimes are processed semantically. The classic phenomenon first described by Stroop (1935) is one widely cited example of an effect which shows that an 
unattended attribute of an attended stimulus has been processed; but this is not strong evidence against early selection models, because there is evidence that attention is allocated to whole objects, not just to component features (see, e.g., Duncan, 1984; Treisman, Kahneman, \& Burkell, 1983).

In the present experiments, an especially impressive case of semantic processing of unattended information was examined-the flanker compatibility effect (FCE), which has been studied extensively by $C$. W. Eriksen and his colleagues, among others (e.g., B. A. Eriksen \& C. W. Eriksen, 1974; C. W. Eriksen \& Schultz, 1979). Experiments demonstrating the FCE typically involve one of two focused attention tasks. In the linear displays task, subjects are presented with rows of letters, and they are instructed to respond to the middle letter (relevant and attended) and to ignore the flanker letters (irrelevant and, presumably, unattended). Target letters are assigned to two (as in C. W. Eriksen \& Schultz, 1979) or four (as in Miller, 1988) response keys, and the subject must press the response key assigned to the attended letter. In this situation, the flanker letters produce large response compatibility effects, indicating that they have been identified even though they are unattended. That is, when the unattended letters are targets assigned to the same response as the attended letter, responses are much faster than when unattended letters are targets assigned to a different response. This phenomenon defines the FCE.

The FCE has also been obtained in a cuing task (see, e.g., C. W. Eriksen \& Hoffman, 1973; C. W. Eriksen \& St. James, 1986; Yantis \& Johnston, 1990). ${ }^{2}$ In this task, the display consists of a number of letters (typically eight) arranged in a circle around the fixation point. Prior to display onset, a cue directs the subject's attention to one of the possible locations, and the subject must respond to the letter at that location while ignoring the others. Again, the presence of target letters in unattended display locations can influence RT.

The FCE is an important source of evidence in the controversy surrounding early, as opposed to late, selection models. On the surface, the FCE causes problems for early selection models, because it shows that completely irrelevant visual stimuli are not fully excluded from semantic processing, even when it would be desirable to do so. Indeed, some theorists (e.g., van der Heijden, 1981) regard semantic effects of unattended stimuli as the most compelling evidence that subjects cannot restrict identification to a part of a stimulus display.

On the other hand, as is discussed in detail in the introduction to Experiment 1, the FCE decreases with increasing separation between target and flankers (see, e.g., B. A. Eriksen \& C. W. Eriksen, 1974). The dependence of the FCE on physical characteristics of the display suggests problems for the late selection view that stimuli are fully identified regardless of attention (but see Duncan, 1981, for a late-selection discussion of spatial effects). Instead, by showing that location is useful for selection, it supports an early selection model of a spotlight (see Pos- ner, 1980) or zoom lens (see C. W. Eriksen \& St. James, 1986).

One reasonable compromise theory, given the available evidence about the FCE, is that the mechanism for early selection attenuates unattended stimuli, instead of completely blocking them from further processing (Treisman, 1964). According to this model, selection takes place early, on the basis of physical properties of stimuli (e.g., location), but unselected stimuli are merely attenuated rather than filtered out entirely. Because unattended stimuli receive reduced semantic analysis instead of being discarded, they may sometimes have semantic effects even though selection occurs prior to identification. Under some conditions, of course, this reduced semantic analysis might influence behavior. On this view, the fact that an FCE is obtained in the first place is taken as a reflection of imperfect early selection, whereas the decrease in the FCE with increasing visual angle is taken as a reflection of the more efficient selectivity possible with increasing physical separation.

A functionally very similar notion is that selection can occur at two or more different levels (Johnston \& Heinz, 1978; Yantis \& Johnston, 1990). The existence of the FCE would suggest that unattended stimuli receive some semantic processing, which suggests that some selection takes place after semantic analysis. On the other hand, the influence of visual angle on the FCE would be direct support for selection at an early level.

Given the suggestion that at least some selection can take place at an early level of analysis, the present series of studies was undertaken to try to find an experimental manipulation that would completely eliminate the FCE (cf. Egeth, 1977; Francolini \& Egeth, 1980; Harms \& Bundesen, 1983; Miller, 1987). If the FCE does arise from the partial failure of an inherently limited early selection mechanism (see, e.g., Broadbent, 1982), it may well be possible to discover experimental manipulations that will compensate for the limitation and thereby eliminate the effect. Such manipulations, which define boundary conditions between complete and partial early filtering, would be quite informative about the characteristic limitations of the early selection mechanism.

In the course of this investigation, it was also possible to determine whether or not most of the experimental manipulations influence the size of the FCE, although lack of an appropriate control occasionally prevented this. Experimental manipulations that change the size of the FCE without removing it are also of interest, of course, because their effects add to empirical knowledge about factors influencing the efficiency of selective attention (whether it takes place early or late). Nonetheless, the most theoretically decisive result would be the discovery of a manipulation that eliminates the FCE, because this result would significantly strengthen the still-debated case that some selection does take place at an early level (cf. Allport et al., 1985).

Of course, the search for boundary conditions of the FCE must be guided by specific hypotheses about why 
early selection is incomplete in the first place. For example, Harms and Bundesen (1983) suggested the possibility that the FCE might result partly from poor perceptual segregation of the target from the noise, which could occur if a preattentive process grouped the whole display as a single unit. This suggestion was plausible, because there is evidence that attention is selectively allocated to objects within the visual field and that all parts of the selected object receive attended processing (e.g. , Driver \& Baylis, 1989; Duncan, 1984; Kahneman \& Henik, 1981; Treisman et al., 1983). Harms and Bundesen (1983) therefore conducted an experiment in which the target and flanker letters were presented in different colors to facilitate perceptual segregation. Responses were faster overall with different- than they were with same-color flankers, suggesting that perceptual segregation had been influenced by color. The FCE was still present, however, indicating that segregation by color is not sufficient for early filtering. In fact, the effect was not even diminished in size relative to a same-color control condition, ${ }^{3}$ suggesting further that, once attended and unattended stimuli are differentiated by location, selection does not use any further perceptual cues enabling differentiation.

In an analogous endeavor, Miller (1987) examined the hypothesis that the FCE arises only because flankers are task-relevant. According to this notion, the task requires subjects to look actively for a set of target letters on which responses are based, and the internal representations of these target letters are therefore primed in semantic memory. Because they are primed, response-relevant letters are recognized even when they are supported only by the weak evidence available from attenuated processing of items in unattended locations (Treisman, 1964). To investigate this possibility, Miller (1987) examined effects of flanker letters that were not targets assigned to either response. Across experimental trials, the identities of these flanker letters were correlated with the correct response (e.g., the correct response might be "left" on $90 \%$ of the trials for which the letter $X$ was a flanker). Although the subjects did not seem to be aware of these correlations, response times were clearly influenced by them (e.g., the "left" response was faster than the "right" response when X was a flanker). Thus, Miller (1987) rejected the claim that flankers are processed only because their identities have been primed by task relevance.

Yantis and Johnston (1990) have also argued that the FCE arises because of suboptimal conditions for attentional selection. They discussed a number of factors that might cause some attention to spill over onto the irrelevant items, and they reported experiments in which the FCE was almost entirely eliminated. Unfortunately, they did not examine the effects of various manipulations separately, so it is impossible to know just which of their procedural changes was responsible for the reduction in the FCE. In the present experiments, some of the manipulations that they used, as well as some additional ones, were examined in an attempt to evaluate the influence of particular manipulations on the FCE. Moreover, although
Yantis and Johnston (1990) were extremely impressed at how small the FCE became in their experiment, others might be equally impressed at its robustness, given that they were not able to eliminate it entirely even though that was their aim. Clearly, then, the necessary conditions for completely successful early selection have not yet been identified.

\section{OVERVIEW OF THE PRESENT EXPERIMENTS}

In the following focused attention experiments, five hypotheses were tested, in order to find out why early selection merely attenuates unattended stimuli instead of filtering them out completely. We restricted our attention to the linear displays task, since it has been studied experimentally the most.

In essence, each hypothesis amounts to a claim that the flanker letters are not totally unattended-despite the instructions and the nature of the task-but that some attention "leaks over" to the flankers, thereby enabling both their identification and the FCE (cf. Yantis \& Johnston, 1990). Each hypothesis suggests a different manipulation that should permit early selection to take place, thereby eliminating the FCE, and each is somewhat plausible on the basis of other attentional phenomena.

The first hypothesis, tested in Experiments 1 and 2, is that the FCE arises because the focus of attention has poor spatial resolution. Several researchers have suggested that spatial attention cannot be focused more narrowly than about $1^{\circ}$ of visual angle (e.g., Broadbent, 1982; B. A. Eriksen \& C. W. Eriksen, 1974), and in most experiments this would be insufficient spatial resolution to completely exclude the flanker letters. In Experiments 1 and 2, this view was tested by increasing the visual angle between target and flankers, with flanker size meanwhile increased in order to assure adequate visual acuity for their potential recognition. The results indicate that flankers are still identified, though they have smaller and qualitatively different effects, even if they are a considerable distance from the relevant letters.

A second hypothesis, tested in Experiment 3, is that the FCE arises because of subjects' inability to maintain attentional focus on a fixed location. Using a detection task, Posner and his colleagues (e.g., Posner \& Cohen, 1984; Posner, Cohen, Choate, Hockey, \& Maylor, 1984; Posner, Snyder, \& Davidson, 1980) have shown that the benefit from having the stimulus appear in an expected rather than an unexpected location is much larger if the expected location changes from trial to trial than if it remains constant across a block of trials. This suggests that attention to a given spatial location is an active process that is difficult to maintain across a large number of trials. In the linear displays task, of course, attention must be maintained on a given location throughout the entire experiment. Thus, in that task, the FCE might be produced by some attention's spilling over onto the flankers if subjects could not maintain concentrated attention on the location of the target. Although the presence of the FCE in cuing 
tasks with circular displays shows that varying the attended location is not sufficient to prevent the identification of unattended items, it is still possible that this factor may contribute to the effect of unattended items. In Experiment 3, the effect of varying the location of attention was evaluated by cuing the subject to attend to either the middle letter or the flankers, varying randomly from trial to trial. The FCE was not significantly influenced by this manipulation, contradicting the second hypothesis.

A third hypothesis, tested in Experiments 4 and 5 , is that the FCE arises because it is impossible for subjects to focus perfectly on a location from which no visual information is being extracted. In the standard focused attention task, the subject is asked to focus in advance of stimulus onset, and so, at the time when focusing must occur, there is nothing to be processed at the to-beattended location. According to the necessary object hypothesis, complete focusing requires an informative object on which to focus. Thus, the FCE arises because attention cannot be focused completely on a perceptually empty location. This is not to deny that attention can differentially favor a given location in the absence of any stimuli to be processed at that location, only that irrelevant information can be completely filtered out without a relevant stimulus to process. In Experiments 4 and 5, a rapid serial visual presentation (RSVP) version of the linear displays task was used, and the results indicate that the FCE occurs even if the relevant display location contains objects to which visual attention can be directed, contrary to the necessary object hypothesis. It is difficult to know whether or not this manipulation changes the size of the FCE, because the unusual visual conditions make it difficult to construct an appropriate control condition.

A fourth hypothesis, tested in Experiment 6, is that the FCE arises because of subjects' inability to filter out visual stimuli that appear abruptly in the visual field (onsettransient stimuli). Onset-transient stimuli are known to have a strong tendency to grab attention in visual search tasks (Hoffman, Nelson, \& Houck, 1983; Jonides \& Yantis, 1988; Yantis \& Jonides, 1984). If onset-transient stimuli always demand some attention because of their transient properties, then the FCE could result from obligatory, partially attended processing of flankers. In Experiment 6 , no difference in the FCEs produced by onsetand offset-transient flankers was found, thus contradicting the fourth hypothesis.

A fifth hypothesis, tested in Experiments 7-10, is that the FCE arises because of subjects' inability to prevent analysis of all stimuli in an impoverished visual field. Many theorists have emphasized the perceptual system's capacity for massive parallel computation (e.g., Allport et al., 1985), and it is possible that such machinery cannot be shut down even if it can be selectively directed. We will refer to this as the perceptual underload hypothesis, because it attributes the processing of irrelevant letters to insufficient demand on the perceptual system. In Experiments 7-10, this hypothesis was tested with a task in which a variable number of relevant letters appeared between irrelevant flankers. The results show that the FCE is not eliminated, possibly not even reduced, as the number of relevant display locations increases from two to eight. Thus, perceptual underload does not account for the FCE.

The failures of these manipulations to eliminate the FCE, in conjunction with previous failures to eliminate the effect (see, e.g., Egeth, 1977; Harms \& Bundesen, 1983; Miller, 1987; Yantis \& Johnston, 1990), suggest that early selection rarely, if ever, completely excludes unattended stimuli from semantic analysis (i.e., attenuation to a strength of 0 ).

\section{EXPERIMENT 1}

One very attractive hypothesis is that unattended stimuli cannot be excluded completely from processing because relevant and irrelevant stimuli are too close together (see, e.g., Broadbent, 1982). Many view spatial attention as analogous to a spotlight (e.g., Posner, 1980) or a zoom lens (e.g., C. W. Eriksen \& St. James, 1986), and any such mechanism would necessarily have some limit in its spatial resolution. Flankers would have effects, according to this strong distance hypothesis, because they are so close to the relevant letter that they cannot be excluded from attended processing.

There have been several studies of the influence of separation on the FCE. Before reviewing their results, however, I should emphasize that for the present purposes the critical question is whether or not the FCE is eliminated when flankers are presented reasonably far from the target. To increase separation may well reduce the FCE, but, as long as some FCE remains, early selection cannot have been completely successful.

B. A. Eriksen and C. W. Eriksen's (1974) original study of the FCE included a manipulation of target/flanker separation, which showed that the FCE decreased with increasing separation. The FCE was still present even at the largest separation tested $\left(1^{\circ}\right)$, however, so this study does not support the strong distance hypothesis. Egeth (1977) reported that the FCE was still present even with $2^{\circ}$ between targets and flankers, in spite of the fact that $2^{\circ}$ is generally considered to be a separation sufficient to ensure no spillover to the unattended location. Similarly, Gathercole and Broadbent (1987) found the FCE at their largest target/flanker separation $\left(1.9^{\circ}\right)$, although it was only obtained when the flankers were presented slightly before the target.

In a few studies, target/flanker separation has been varied over more extreme ranges, but, for various reasons, the processing of unattended stimuli has always been studied with variants of the Stroop (1935) task rather than with the FCE. A technical problem in these studies is that the unattended material loses visual acuity as it is moved farther from the target, which is always presented at fixation. One must therefore take special steps, such as increasing the unattended material's size, to ensure that any reduction in the effect of unattended material is due to 
more efficient filtering rather than to less raw input strength (see Egeth, 1977). Using Stroop interference, Gatti and Egeth (1978), Hagenaar and van der Heijden (1986), and Merikle and Gorewich (1979) all sought to separate the effects of spatial separation and retinal acuity, and they all concluded that acuity loss-not distancewas probably responsible for any decrease in interfering effects associated with increased separation. For example, Hagenaar and van der Heijden (1986) found that the Stroop effect did not depend at all on the visual angle $\left(1^{\circ}-2^{\circ}\right)$ separating the color patch from the interfering word, even when the location of the color patch was cued in advance of stimulus onset. Despite these studies, for the present arguments it would also be desirable to find out whether or not the FCE is eliminated with target/ flanker separation of more than $2^{\circ}$; the first two experiments were designed for that purpose.

It should also be noted that increasing target/flanker separation has been found to eliminate the FCE in studies with the cuing task, in which acuity can be controlled by presenting targets and flankers at equal distances from fixation. For example, C. W. Eriksen and St. James (1986) and Yantis and Johnston (1990) presented eight letters arranged around an imaginary circle centered at fixation (see also C. W. Eriksen \& Hoffman, 1973). FCEs were usually obtained for response-related flankers immediately adjacent to the relevant location on the circle, but not for flankers in more distant locations. ${ }^{4}$

Even if FCEs do disappear for flankers more than one position away from the target, however, it does not demonstrate the strong distance hypothesis. With this stimulus display, distance is confounded with the number of intervening items between the relevant location and the flanker, and the disappearance of the FCE could be attributable to the intervening items rather than the distance per se. Three pieces of data support this interpretation. First, C. W. Eriksen and St. James (1986) found that the FCE disappeared for nonadjacent flankers even though their circle was only $1.5^{\circ}$ of visual angle in diameter (individual letters were about $0.3^{\circ}$ in height and width). If the FCE disappears with such small target/flanker separations, presumably something other than sheer distance is responsible for its absence. Second, Yantis and Johnston (1990, Experiment 4) varied the size of the circle, so interletter distances (edge to edge) varied from about $2^{\circ}$ to $0.2^{\circ}$. They found no effect of interletter distance on the FCE, contrary to the strong distance hypothesis. Third, using displays with no stimuli intervening between targets and flankers, Murphy and C. W. Eriksen (1987) found an FCE of approximately $25 \mathrm{msec}$ with the target $3^{\circ}$ to one side of fixation and a flanker $3^{\circ}$ to the other. ${ }^{5}$ This finding is not completely disastrous for the strong distance hypothesis, however, because the time between onset of the cue and onset of the display (stimulus onset asynchrony, or SOA) was only $175 \mathrm{msec}$. It is generally thought that 200 msec may be needed for complete focusing of attention (see, e.g., C. W. Eriksen \& St. James, 1986), so this FCE may have resulted from partially attended processing of the irrelevant item.
If the disappearance of the FCE for letters not adjacent to the relevant location is due to the number of intervening items rather than distance per se, then it does not indicate that early selection was completely successful. One alternative explanation is that early selection fails only in that identification also includes the nearest unattended neighbors of the relevant location. On this view, nonadjacent response-relevant flankers are shielded from identification by adjacent response-irrelevant flankers, so that early selection fails, though not to the point of identifying everything in the visual field (but see Driver \& Baylis, 1989). Another alternative is that the shielding takes place during the response activation process, even though all stimulus letters were identified.

In summary, it is certainly not clear that the FCE can be eliminated simply by separating the flankers from the target by several degrees of visual angle. In view of the attractiveness of the strong distance hypothesis and the absence of decisive tests, however, further experiments to examine this question seemed necessary.

In Experiments 1 and 2, a standard focused attention task was used, but in one condition flankers were presented approximately $4.6^{\circ}$ from the relevant center letter. To ensure adequate acuity for the flankers, these letters were presented in an unusually large size. Relevant letters were presented in the same size as flankers to avoid a possible confound: If relevant letters were smaller than flankers, it would be possible that flankers might attract attention by virtue of being the largest items in the display. ${ }^{6}$

\section{Method}

Apparatus and Stimuli. The stimuli were presented and responses and response latencies recorded with an IBM-PC-compatible computer equipped with an Enhanced Graphics Adaptor and attached to an NEC Multisync display monitor. Responses were made by pressing the " $\mathrm{Z}$ " and " $\%$ " (slash) keys on the standard computer keyboard with the left and right index fingers.

The stimuli were uppercase consonants drawn as light lines against the dark background of the computer monitor. Each stimulus was about $2.4^{\circ}$ wide and $4.8^{\circ}$ high; these sizes were chosen to ensure that the letters were clearly visible even when presented in the visual periphery. In the wide separation condition, there was a minimum of $4.6^{\circ}$ edge-to-edge separation between the target and each flanker. In the narrow separation condition, there was a minimum of $0.9^{\circ}$ separation.

Subjects and Procedure. The subjects were 36 undergraduates recruited on the campus of the University of California, San Diego. Each subject served in a single session lasting about $50 \mathrm{~min}$ and received either a monetary reward or credit toward an undergraduate course requirement.

For each subject, two randomly selected consonants were assigned as targets for each of the two response keys; these assignments remained constant throughout the session. One other consonant was randomly selected for use as a neutral flanker. Each session was composed of three blocks of 200 experimental trials. Blocks began with four warm-up trials randomly selected with replacement from the experimental trials, and a new random order of trials was generated for every block.

Within each block, there were five tests of each of 40 types of trials. The types of trials were defined by the factorial combination of two possible degrees of separation (wide vs. narrow), four possible target letters, and five possible flanker identities (any of 
the four possible targets or the neutral letter). The two flankers were identical to each other on all trials. Trials on which the response was made in fewer than 200 msec or more than $2 \mathrm{sec}$ were discarded and rerun at a randomly selected point later in the block.

The subjects were informed that they would be presented with rows of three letters and that they should respond to the middie letter and ignore the outside letters. They were given the assignment of target letters to response keys and instructed to respond as quickly as possible without making too many errors.

A trial began with the presentation for $500 \mathrm{msec}$ of a fixation cross at the center of the display. About $500 \mathrm{msec}$ after the offset of the fixation cross, the row of three letters appeared, and it remained on the screen until the subject responded. After each response, the subject was given feedback regarding accuracy (i.e., the word "right" or "wrong"), which lasted $600 \mathrm{msec}$ for correct responses and $1.2 \mathrm{sec}$ for errors. The intertrial interval was about 500 msec.

\section{Results and Discussion}

Mean reaction times (RTs) and percentages of correct responses (PC) were computed for each subject as a function of block, separation, response, and flanker identity (identical, response compatible, neutral, and response incompatible). Figure 1 shows the averages across subjects as a function of separation and flanker identity.

At the wide separation, flanker identity had a significant effect on RT $[F(3,105)=6.9, p<.001]$. Pairwise comparisons indicated that the response-compatible condition produced faster responses than did any of the other three, among which there were no significant differences. The factorial analysis also indicated that RT decreased across the three blocks of practice $[F(2,70)=6.29, p<$ $.01]$, and no other effects or interactions were significant. There were no significant sources of variance in the factorial analysis of PC.

At the narrow separation, there was a significant effect of flanker identity on both $\operatorname{RT}[F(3,105)=30, p<$

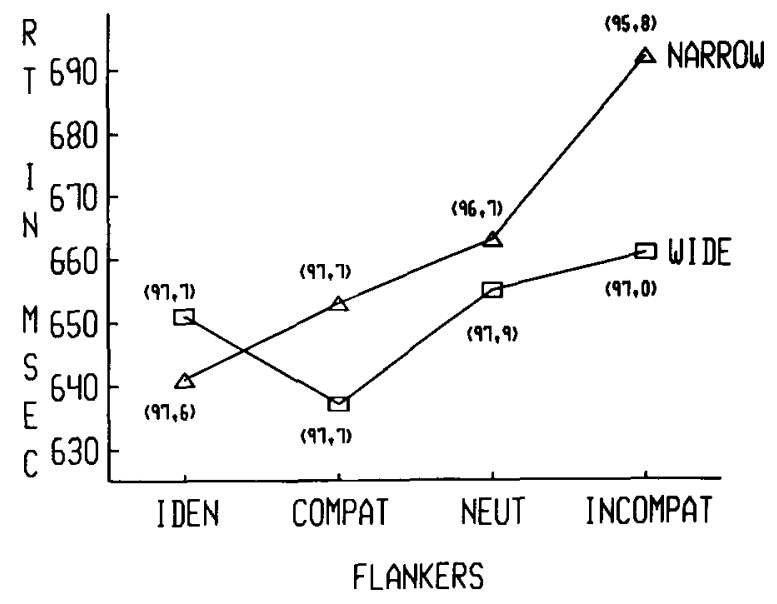

Figure 1. Experiment 1 (large targets, large flankers): Reaction time (RT) and percentage of correct responses (in parentheses) as a function of flanker identity (identical, response compatible, neutral, response incompatible) and separation between target and flankers. In the narrow separation condition, there was slightly under $1^{\circ}$ of visual angle between target and fanker edges; in the wide separation condition, there were almost $5^{\circ}$.
$.001]$ and $\mathrm{PC}[F(3,105)=6.6, p<.001]$. Pairwise tests on RT indicated that responses were significantly faster with identical flankers than with any of the other types, and that responses were faster with neutral than with response-incompatible flankers. RT also decreased across blocks $[F(2,70)=7.3, p<.01]$, and this practice effect was larger for right- than for left-handed responses $[F(2,70)=5.87, p<.01]$.

The main conclusion of this experiment is that, when they are large enough, irrelevant flanker letters produce compatibility effects even when they are separated from relevant target letters by almost $5^{\circ}$. Such effects indicate that the flankers were recognized, so it is clear that this separation is not sufficient for early selection to completely exclude unattended stimuli from semantic processing. Of course, further research may demonstrate that the FCE can be eliminated with an even larger separation (while controlling for acuity), but imperfect visual selectivity over such a large area suggests that the imperfect focus of an attentional spotlight is not the sole cause of the FCE.

Although any pattern of flanker effects shows that wide separation is not sufficient to prevent flanker identification, the rather unusual pattern of effects at the wide separation deserves comment. The usual pattern is that obtained in the narrow separation condition: Identical and response-compatible flankers produce slightly faster responses than neutral flankers, whereas responseincompatible flankers produce much slower responses than neutral flankers. With wide separation, however, responses were especially fast only for responsecompatible flankers, and the other three conditions did not differ significantly. ${ }^{7}$ There is no clear-cut explanation for the unusual pattern of semantic effects at the wide separation, but it could result from a change in the relative times at which flankers and center letters were recognized (cf. Gathercole \& Broadbent, 1987). It seems likely that the decrease in acuity at the wide separation would delay flanker identification, and there is evidence that the effects of different types of flankers have different time courses (see, e.g., Flowers \& Wilcox, 1982). Thus, the unusual pattern of effects may be due to temporal differences rather than fundamental differences in processing of flankers at the two separations.

\section{EXPERIMENT 2}

Although the previous experiment demonstrated an FCE with flankers widely separated from targets, another demonstration of the effect is desirable for two reasons. First, the effect had an unusual form, which tends to raise the possibility of a Type I error. Second, it is possible that the effect resulted from the unusually large size of the relevant letters used in the previous experiment. There is evidence that the size of the attentional focus varies with the expected target size (see Umilta, 1988, for a review, or LaBerge, 1983, for a particularly elegant demonstration). Perhaps the extent of attentional spillover (i.e., lack of resolution) also varies with the size of the attended area. 
In Experiment 1, for example, the FCE would result if attention could not be focused more finely than about three times the size of the expected target. In Experiment 2, therefore, smaller target letters were used, but the flankers remained the same size as in Experiment 1 to avoid acuity problems. $^{8}$

\section{Method}

Forty-two subjects were tested, using the apparatus and procedure from Experiment 1. The only change was that the target letters were reduced in size to a height of $0.95^{\circ}$ of visual angle.

\section{Results and Discussion}

Figure 2 shows mean RT and PC as a function of flanker identity and target-flanker separation. In analyses of variance (ANOVAs) including only the data from the condition with wide separation, flanker type had a significant effect on both RT $[F(3,123)=3.4, p<.025]$ and PC $[F(3,123)=3.3, p<.025]$. Flanker type also significantly affected RT and PC in the narrow separation condition $(p<.01)$. Analyses combining data from both separations indicated that the flanker effect on RT was significantly larger at the narrow separation than at the wide one $[F(3,123)=3.4, p<.025]$, but that there was no significant interaction for $\mathrm{PC}(p>.5)$.

The replication of the FCE at the wide separation in Experiment 2 further compromises the hypothesis that insufficient separation is the only cause of leakage past an early selection mechanism. Given that the FCE is obtained with separations of approximately $5^{\circ}$ between target and flanker, it is difficult to see how the effect can be attributed to a limited spatial resolution.

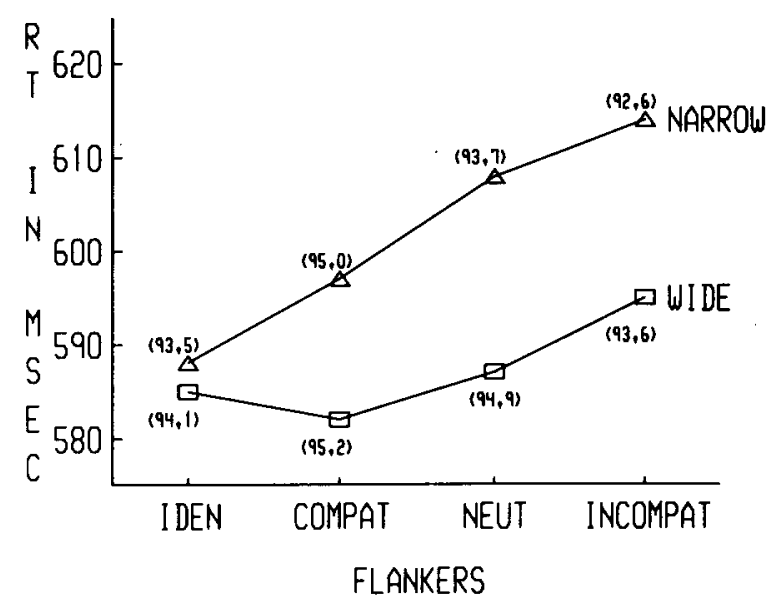

Figure 2. Experiment 2 (small targets, large flankers): Reaction time (RT) and percentage of correct responses (in parentheses) as a function of flanker identity (identical, response compatible, neutral, response incompatible) and separation between target and flankers. In the narrow seperation condition, there was slightly under $1^{\circ}$ of visual angle between target and flanker edges; in the wide separation condition, there were almost $5^{\circ}$.
Of course, it is still possible that a large separation might eliminate the FCE under other conditions. As noted above, early attenuation at a given separation might be less successful when there is a large target, as in Experiment 1, or when the flankers are larger than the target, as in Experiment 2. Nonetheless, it seems clear from the present results that a large separation is not enough to prevent identification of unattended flankers, as might have been expected. This suggests that earlier failures to find the FCE with a large separation may actually have been due to the confounded factor of number of intervening items (see, e.g., C. W. Eriksen \& St. James, 1986).

\section{EXPERIMENT 3}

As noted in the introduction, there is evidence that attention to a given spatial location is more complete and/or effective if the attended location varies from trial to trial than if it is constant across a block of trials (see, e.g., Posner \& Cohen, 1984; Posner et al., 1984; Posner et al., 1980; but see also Bonnel, Possamai, \& Schmitt, 1987, and Hillyard, Munte, \& Neville, 1985, for examples of good attentional selectivity with constant attentional allocation). One explanation for this finding is that active processing is required for spatial attention to become focused, and that subjects do not or cannot maintain this active processing unless the location to which they must direct attention varies (see, e.g., Spencer, Lambert, \& Hockey, 1988).

In the linear displays task, target location has been constant across a block of trials (see, e.g., C. W. Eriksen \& Schultz, 1979). Perhaps the imperfect attentional selection in this paradigm (i.e., the effect of unattended flankers) is attributable to the constancy of the target location. If so, constant target location would be an important boundary condition of the FCE.

Of course, the presence of the FCE in the cuing task (see, e.g., C. W. Eriksen \& St. James, 1986) argues against this hypothesis, because in that task the target location varies from trial to trial. Nonetheless, in Experiment 3, the FCE in linear displays was measured under conditions with constant as opposed to varied relevant locations. This comparison serves two purposes. First, it allows us to determine whether the FCE is still present in linear displays even when target location is varied. Second, it allows a direct test of whether or not the size of the FCE is influenced by the constancy of the relevant location, something that cannot be determined from previous results with either the linear displays task or the $\mathrm{cu}$ ing task.

Each subject was tested in three blocks of trials. In one block, the center letter was always relevant. In a second block, the flankers were always relevant. In a third block, the center letters were relevant on some trials and the flanker letters were relevant on the others, as indicated by a precue. 


\section{Method}

Twenty-four subjects were tested with the same basic apparatus, stimuli, and procedure as in Experiment 1; only the differences will be described here.

The stimulus letters were about $0.56^{\circ}$ wide and $0.84^{\circ}$ high, with a center-to-center separation of about $1.12^{\circ}$. Each trial began with the appearance, for about $1.3 \mathrm{sec}$, of one or two horizontal bars underlining either the center location or the two flanker locations. The row of letters then appeared about $0.3^{\circ}$ above the underline(s), and it remained on the screen until the subject responded. In blocks with constant locations, the underline(s) always appeared in the same place(s) from trial to trial; and in blocks with varied locations, the locations of the underline(s) were randomly selected.

The order of the three blocks was counterbalanced across four groups of subjects. Because the main comparison was that between constant and varied locations, half the subjects were tested with constant locations first and varied locations second, and half were tested in the reverse order. Within each of these two groups, half were tested first with the center as the constant relevant location, and half were tested first with the flankers as the constant relevant location.

Each of the two blocks with constant locations consisted of 100 trials: 5 trials with each combination of four targets and five distractors. The block with varied locations consisted of the same 200 trials randomly intermixed. Each block began with 20 practice trials, randomly selected with replacement from the experimental trials of that block.

\section{Results and Discussion}

Figure 3 shows average RT and PC as a function of constant or varied attention and flanker identity. The analysis of variance of RT revealed significant main effects for both flanker identity $[F(3,60)=12.87, p<.001]$ and attention constancy $[F(1,20)=11.9, p<.01]$. The interaction of these two factors did not approach significance $[F(3,60)=2.06, p>.10]$. In any case, the observed direction of interaction is contrary to the hypothesis, because the effect of flankers was slightly larger with the attention varied $(44 \mathrm{msec})$ than it was with the attention fixed $(25 \mathrm{msec})$. Clearly, there is no evidence

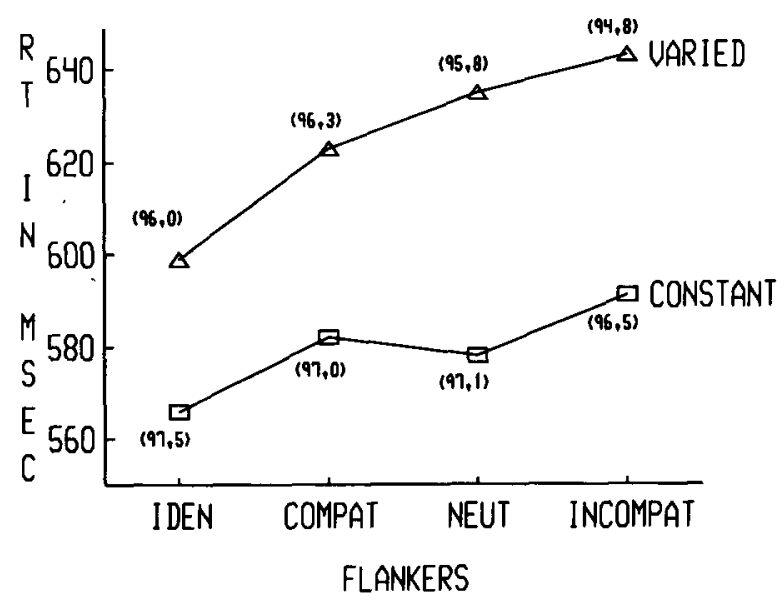

Figure 3. Experiment 3: Reaction time (RT) and percentage of correct responses (in parentheses) as a function of flanker identity (identical, response compatible, neutral, response incompatible) and constant versus varied locus of spatial attention.

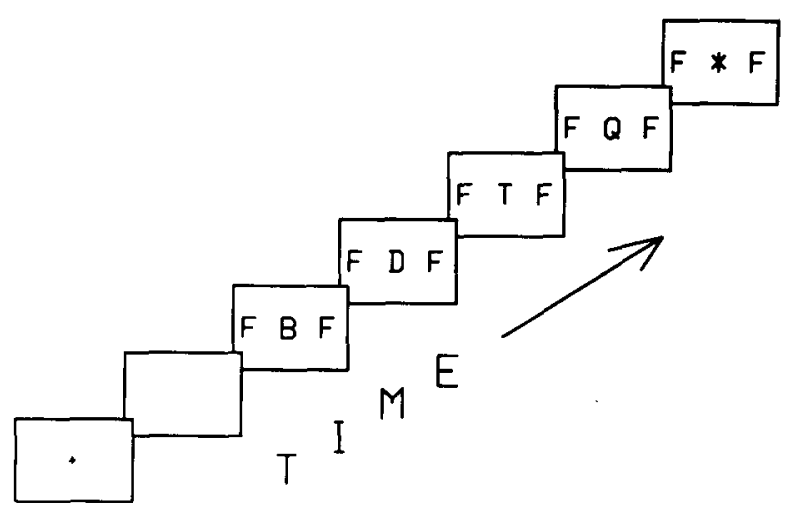

Figure 4. Rapid serial visual presentation (RSVP) version of the focused attention paradigm.

that variations in the locus of attention can diminish the FCE, so location constancy cannot be responsible for imperfect early selectivity. The location of the target (center vs. flanker position) produced neither a main effect nor an interaction with flanker identity or attention constancy.

\section{EXPERIMENT 4}

Perhaps it is not the constancy but rather the emptiness of the attended location which prevents the early selection mechanism from fully excluding other locations from processing. After all, prior to target onset, there is no stimulus to be processed at the location on which subjects are asked to focus. At most, a fixation point may appear, but this stimulus requires no processing because it is completely predictable. Perhaps attention cannot be perfectly confined to an empty location, as is needed for complete exclusion of unattended stimuli, but it can only be so confined when it is directed to an informative visual stimulus.

Experiments 4 and 5 were performed to test this necessary object hypothesis, according to which perfect focusing requires an object of focus. In these experiments, a focused attention task was used, with rapid serial visual presentation (RSVP) of letters in the relevant center location of the display. The sequence of events on any given trial is shown in Figure 4. A fixation sign ("+") was displayed for $800 \mathrm{msec}$; then it disappeared for about $500 \mathrm{msec}$. Then, five frames were presented in immediate succession, each frame lasting $200 \mathrm{msec}$. Each frame had the same flanker letters, so these appeared to remain constant throughout the trial. The relevant center character, however, changed randomly from frame to frame. This character was a target letter in exactly one of the first four frames, and the fifth frame always contained an asterisk in the center.

If the necessary object hypothesis is correct, the FCE should be confined to the first frame in this experiment. That frame provides an object on which to focus, and thereafter it should be possible to remain focused on the 
center location for the rest of the trial, thus eliminating the effect of the flankers.

It should be noted that some reduction in the FCE across frames is to be expected even if the necessary object hypothesis is not correct. The FCE is known to disappear if the flankers are presented too much ahead of the target (see, e.g., C. W. Eriksen \& Schultz, 1979), indicating that the semantic effects of the flankers do not persist indefinitely. Even an FCE in the second frame, however, would be evidence against the necessary object hypothesis.

\section{Method}

The subjects were 32 new undergraduates from the pool used in the previous experiments, and the apparatus and procedure were the same except as noted below. A slightly different stimulus font had to be used so that the display could be changed rapidly enough. In this font, the letters were $1.9^{\circ}$ of visual angle in height and $0.76^{\circ}$ in width, and they were constructed from lines that were $0.19^{\circ}$ thick. The edge-to-edge separation between the center and flanker letters was $0.29^{\circ}$.

One consonant was randomly selected to be the target letter for each response, and one was randomly selected to be the neutral flanker. The other consonants were used as fillers (i.e., nontarget letters appearing in the relevant center location), with the constraint that the same filler was never used in more than one frame on a given trial.

Each subject was tested in four blocks of 120 trials, equally divided among the $\mathbf{2 4}$ combinations of two target letters, four frames in which the target might appear, and three types of flankers (compatible, neutral, and incompatible). If on any trial the subject responded before the entire sequence shown in Figure 4 had been displayed, the rest of the sequence was aborted for that trial.

\section{Results and Discussion}

Mean RT as a function of flanker compatibility and target frame is shown in Figure 5, and PC is shown in Figure 6. Overall, responses were faster to targets in later frames than to targets in earlier ones $[F(3,93)=52, p<.001]$. This may have been an artifact of a shifting speed-accuracy tradeoff criterion, because accuracy decreased monotoni-

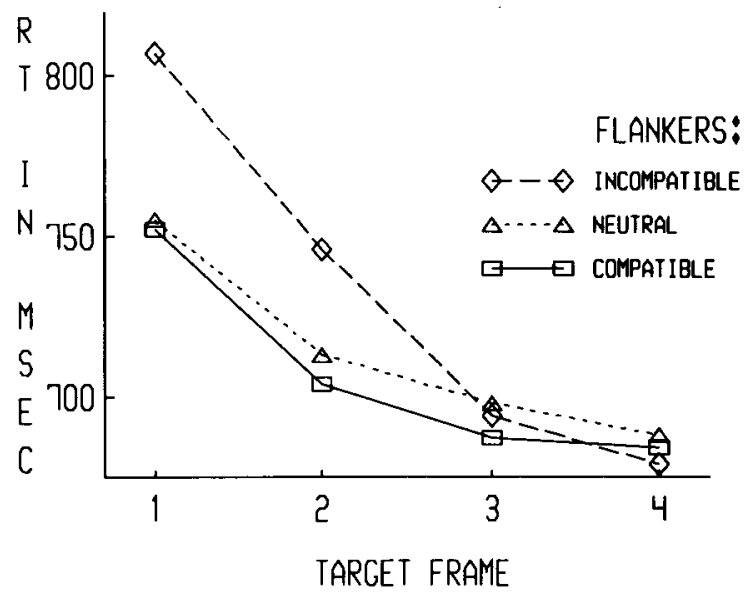

Figure 5. Experiment 4: Reaction time (RT) as a function of flanker identity and frame in which target appeared.

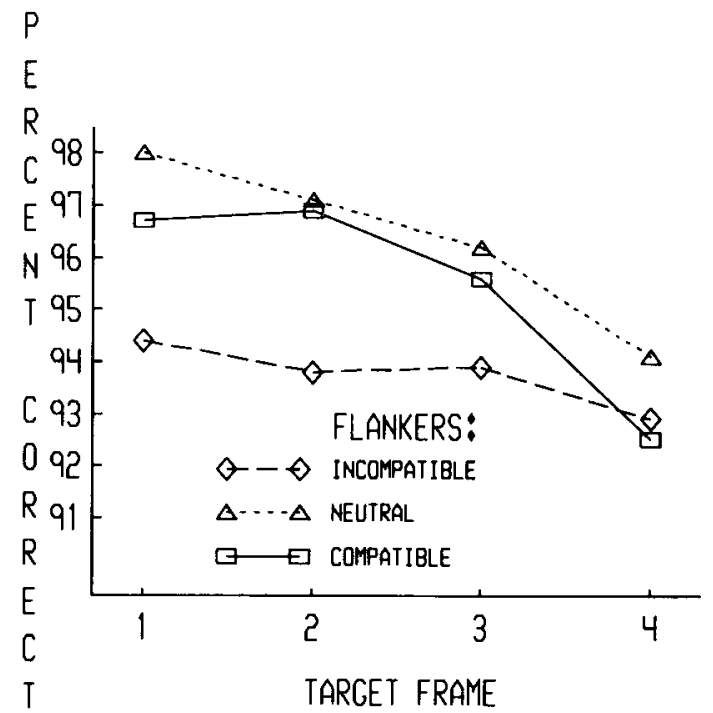

Figure 6. Experiment 4: Percent correct as a function of flanker identity and frame in which target appeared.

cally across frames from $96.4 \%$ to $93.2 \%[F(3,93)=8.84$, $p<.001]$.

Flanker identity also significantly influenced both RT $[F(2,62)=12, p<.001]$ and $\mathrm{PC}[F(2,62)=18, p<$ $.001]$. In both dependent variables, the source of the effect was a disadvantage for the response-incompatible condition relative to the neutral one $(19 \mathrm{msec}$ and $2.6 \%$ correct).

For the necessary object hypothesis, the most important result was the interaction of flanker type and target frame. This interaction was highly significant in the analysis of RT $[F(6,186)=7.8, p<.001]$, but it was not significant in the analysis of PC $[F(6,186)=1.53$, $p>$.15].

As is apparent from Figure 5, flanker identity had no effect on RT for targets in Frames 3 and $4[F(2,62)<1$, $p>.20$, though it had highly significant effects for targets in Frames 1 and 2 [Frame 1: $F(2,62)=13.9, p<$ .001 ; Frame 2: $F(2,62)=12.2, p<.001]$. The effect of flanker identity in the second frame, however, provides some difficulty for the necessary object hypothesis.

The lack of a significant interaction of flanker type and frame position in PC (see Figure 6) is also evidence against the necessary object hypothesis. If flanker effects were confined to the first frame, this interaction should have been significant. Even stronger evidence against the hypothesis comes from the fact that separate ANOVAs for each frame revealed significant flanker effects on PC for all frames but the last [Frame 1: $F(2,62)=9.98, p<$ .001 ; Frame 2: $F(2,62)=14.7, p<.001$; Frame 3: $F(2,62)=3.83, p<.05 ;$ Frame 4: $F(2,62)=1.07$, $p>.25]$. The presence of significant flanker effects at frames other than the first is clearly contrary to the necessary object hypothesis. ${ }^{9}$ 


\section{EXPERIMENT 5}

In an attempt to save the necessary object hypothesis, one could argue that all flanker effects obtained in Experiment 4 resulted from processing that took place before attention was completely focused. After all, the flankers appeared at the same time as the first target did (i.e., in the first frame), so they were initially processed before the hypothesized state of complete focus could have been achieved. Perhaps the consequences of this processing lingered, thereby causing an FCE not only for targets in the first frame but also for targets in the second and (for PC only) third frames.

To test this explanation, it was necessary to examine the effects of flankers presented after the hypothesized state of complete focus had been achieved. In Experiment 5 , then, a second set of flankers was presented for the third and fourth frames. If the necessary object hypothesis is correct, then attention should be locked on to the relevant center location by the third frame, and the identities of the flankers in those frames should have no effect.

\section{Method}

Thirty-two subjects were tested in a slightly modified version of the previous experiment. The only differences involved the fact that the flankers changed at the third frame, so that there was one pair of flankers for the first two frames and a different pair for the last two frames. If the center target appeared in the first or second frame, the flankers for these frames were compatible, neutral, or incompatible letters, as in the previous experiment, and the flankers for the third and fourth frames were asterisks. If the center target appeared in the third or fourth frame, the flankers for the first two frames were asterisks, and the flankers for the last two frames were compatible, neutral, or incompatible letters. Thus, in Experiment 5, the manipulation of flanker type involved the identity of the flanker in the same frame as the center target (and also one adjacent frame, because of the fact that flankers appeared for two frames).

\section{Results and Discussion}

Figures 7 and 8 show mean RT and PC as a function of flanker type and target frame. In the ANOVAs includ-

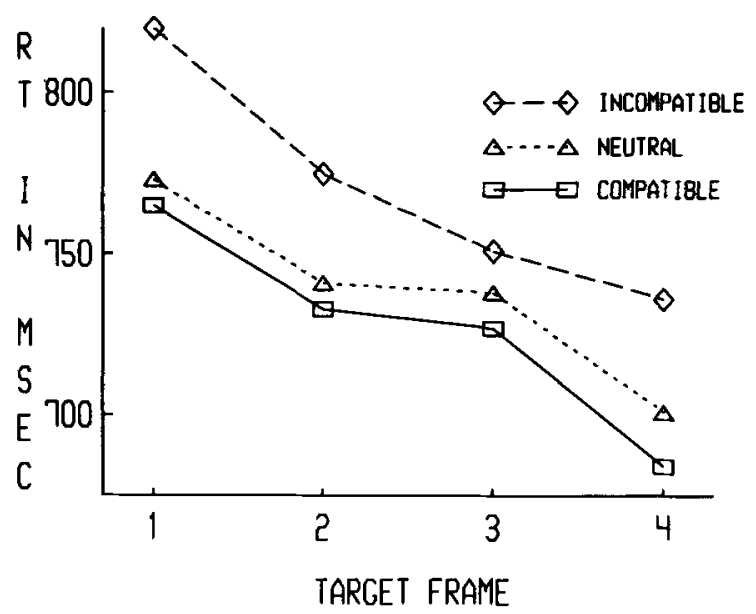

Figure 7. Experiment 5: Reaction time (RT) as a function of flanker identity and frame in which target appeared.

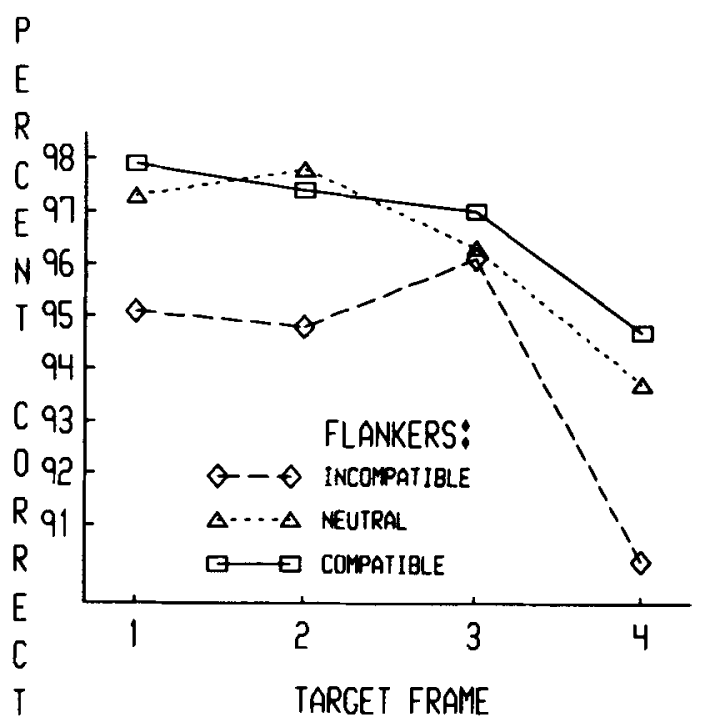

Figure 8. Experiment 5: Percent correct as a function of flanker identity and frame in which target appeared.

ing data from all frames, there were significant main effects of frame [RT: $F(3,93)=13.8, p<.001 ; \mathrm{PC}: F(3,93)$ $=14.2, p<.001]$ and flanker $[\mathrm{RT}: F(2,62)=55, p<$ $.001 ; \mathrm{PC}: F(2,62)=23.7, p<.001]$, as well as a significant interaction between these two factors [RT: $F(6,186)$ $=2.18, p<.05$; PC: $F(6,186)=2.31, p<.05]$.

Separate ANOVAs were computed for each frame position. For RT, the FCE was significant at every position [Frame 1: $F(2,62)=18.7, p<.001$; Frame $2: F(2,62)$ $=16.9, p<.001 ;$ Frame 3: $F(2,62)=4.50, p<.025$; Frame 4: $F(2,62)=25.9, p<.001]$. For PC, it was significant at every position but the third [Frame 1: $F(2,62)$ $=8.89, p<.001$; Frame 2: $F(2,62)=10.5, p<.001$; Frame 3: $F(2,62)=0.73, p>.40$; Frame 4: $F(2,62)$ $=9.86, p<.001]$.

The FCEs obtained with targets appearing in the third and fourth frames provide a strong blow to the necessary object hypothesis, because in these conditions the effects were produced by flankers that did not appear until after the hypothesized state of completely focused attention should have been attained. Clearly, then, an object of perceptual attention is not sufficient for complete focusing of attention to occur. One could try to defend the hypothesis by saying that the complete focus of attention is in fact attained, but that it is then disturbed by the transients produced when the flankers change at the third frame. Experiment 6 was therefore performed to explore the role of visual transients in modulating the FCE.

\section{EXPERIMENT 6}

Abrupt onsets in the visual field (onset transients) are clearly involved in the spatial allocation of visual attention (Breitmeyer \& Ganz, 1976). For example, Jonides (1981) found evidence that attention was automatically shifted toward onset transients that occurred in the visual 
periphery. Yantis and Jonides (1984) found that detection latency for a unique onset-transient target letter was independent of the number of offset-transient distractor letters in the display, and they argued that onset transients attract attention with very high priority.

The power of onset transients to attract attention suggests that they could play an important role in the FCE (cf. Gathercole \& Broadbent, 1987). Perhaps abrupt visual onsets always attract some attention, regardless of the prior spatial distribution of attention across the visual field. If so, unattended flanker letters may have been processed simply because they have always been presented with onset transients. On this view, the FCE should disappear if flankers are instead presented with offset transients.

In Experiment 6, the influence of visual transients was investigated by factorially varying the nature of the transients (onset vs. offset) appearing during presentation of the target and flanker letters. Transients were produced with the method of Yantis and Jonides (1984). Onset transient letters appeared abruptly on the visual display, as in previous experiments in which the FCE was examined. Offset transient letters were revealed by the disappearance of lines from a premask shaped like a figure 8 . This premask was part of the warning/fixation display, but it carried no information about letter identity.

Even if the FCE is not eliminated by offset-transient flankers, it should certainly be reduced. As noted above, an onset-transient stimulus seems automatically to receive more visual attention than an offset-transient stimulus, and it seems reasonable that this should be true even for flankers in irrelevant positions. If the FCE is a function of the amount of processing resources given to the irrelevant flankers, as is presumed in early selection accounts of the FCE and its decrease with increasing separation, the reduction of resources brought about by using offset-transient flankers should produce a concomitant reduction in the FCE.

\section{Method}

Thirty-two subjects were tested with the same basic apparatus and procedure as in the previous experiments. Following Yantis and Jonides (1984), the stimuli were the uppercase letters E, H, $P, S$, and $U$, each of which can be made by deleting lines from a premask shaped like an 8 (Miller, 1989). For each subject, two of the letters were randomly assigned as targets for each of the two responses, and the fifth letter was used as the neutral flanker. The letters were about $2.2^{\circ}$ wide and $4.5^{\circ}$ high, and they were separated by about $3.9^{\circ}$ from center to center.

Each subject was tested in two blocks of 320 experimental trials, preceded by 4 warmup trials. In each block, there were 4 trials in each of the 80 experimental conditions defined by four target identities, five flanker identities, two types of target transients (onset vs. offset), and two types of flanker transients (onset vs. offset). A new random order of trials was generated for each block.

Each trial began with the presentation of a fixation cross in the center of the display for $1 \mathrm{sec}$. At the offset of the fixation cross, a premask display appeared. This display could contain a premask in the target location, in the two flanker locations, in all three locations, or in none of the locations, depending on the randomly selected target and flanker transients for that trial. The premask display remained on the screen for $500 \mathrm{msec}$, at which point the stimulus row appeared.

\section{Results and Discussion}

Averages are shown in Figure 9 as a function of flanker identity, target transients, and flanker transients.

Overall, responses were $32 \mathrm{msec}$ faster with offset than with onset flankers $[F(1,30)=43.6, p<.001]$ and $11 \mathrm{msec}$ faster with onset than with offset targets $[F(1,30)$ $=7, p<.02]$. Furthermore, the advantage for onset targets was greater with offset than with onset flankers $[F(1,30)=24.8, p<.001]$.

The main effect of flanker identity was highly reliable $[F(3,90)=7.9, p<.001]$ and pairwise comparisons indicated that response-compatible flankers produced the fastest responses and that response-incompatible flankers produced responses slower than those produced by neutral flankers.

Most important for the present purposes was that the FCE was certainly not eliminated with offset-transient flankers. In fact, there were not even significant interactions of flanker identity and flanker transients $[F(3,90)=$ $1.35, p>.20$ ], flanker identity and target transients $[F(3,90)=0.95, p>.20]$, or flanker identity, flanker transients, and target transients $[F(3,90)=0.33, p>$ $.20]$. Thus, there is no evidence that the FCE is even influenced by the type of visual transients in the target or distractors. ${ }^{10}$

The ANOVA done on RTs also revealed a significant main effect of practice, in that responses were $39 \mathrm{msec}$ faster in the second block than they were in the first $[F(1,30)=11.6, p<.01]$, and this effect was larger for right- than for left-handed responses. In the factorial analysis of PC, only the effect of flanker identity was reliable $[F(3,90)=4.94, p<.01]$, due to lower accuracy with response-incompatible flankers than with any of the other types of flankers.

The present findings do not suggest that transients are responsible for partial leakage of unattended stimuli past an early selection mechanism. Clearly, the FCE does not

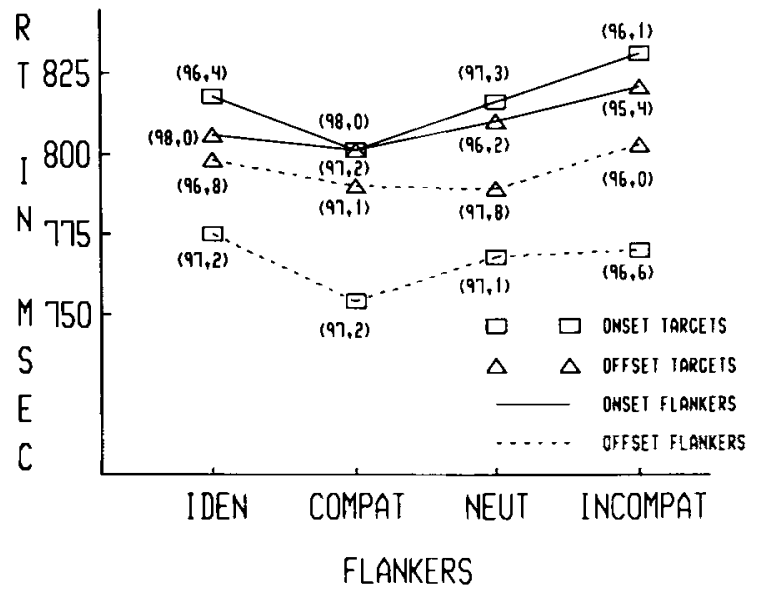

Figure 9. Experiment 6: Reaction time (RT) and percentage of correct responses (in parentheses) as a function of flanker identity (identical, response compatible, neutral, response incompatible) and type of transients in both target and flankers. 
disappear when flankers are presented with offset rather than onset transients. One simple explanation would be that the manipulation of transients was ineffective; but this explanation is untenable. Using the very same stimuli and equipment, we have previously replicated the finding of Yantis and Jonides (1984) that the number of offset distractors has no effect on RT to detect an onset target in a visual search paradigm (Miller, 1989). The success of this replication, which was done with the same equipment and stimuli that were used here, strengthens the case that attention was directed by the transients as we have assumed. Moreover, this explanation is also inconsistent with the large main effects and interaction of the two types of transients in Experiment 6. Responses were slower with onset than with offset flankers and faster with onset than with offset targets, indicating that more attention was allocated to onset than to offset transients. These findings support early selection models by suggesting that the amount of processing capacity given to a stimulus is related to the physical characteristics of its onset. ${ }^{11}$

The fact that transients have no influence on the FCE is quite surprising. As Kahneman and Treisman (1984) have pointed out, the strongest late selection hypothesis is that in which semantic processing of a stimulus is totally unaffected by the amount of attention paid to it; and this hypothesis seems directly supported by the results. As discussed above, there is considerable evidence that transients influence the amount of attention paid to targets and flankers, and these transients did have sizable effects on total RT. Thus, the results suggest that the FCE is unaffected by attention, at least over the range of attention variation produced by the transients. These results therefore constitute strong evidence for the most extreme late selection models, at least in this task (see Reiner \& Morrison, 1983, for an analogous example in another task). The strength of this conclusion must be somewhat limited by the acceptance of a null hypothesis, of course.

At present, it is not clear how to reconcile the strong effects of transients on attention (see, e.g., Yantis \& Jonides, 1984), the reduction in FCE with increasing separation between target and flankers (as in Experiments 1 and 2), and the lack of effect of transients on the FCE in Experiment 6. The first point supports the assumption that onset-transient stimuli get more attention than offsettransient stimuli do, and the second supports the assumption that stimuli obtaining more attention produce larger FCEs. In the face of the null effect, however, it appears that one of these assumptions must be given up, at least in some cases. Recent experiments of Yantis and Jonides (1990) suggest that the first assumption may be wrong, by showing that effects of onset transients are sometimes reduced when attention is strongly focused on one location. In their fourth experiment, however, Yantis and Jonides found evidence for more processing of unattended stimuli presented with onset as opposed to offset transients. In the present Experiment 6, if independence of processing from transients were the explanation for the independence of the FCE from transients, it would be difficult to explain the effect of these transients on overall RT. Another possibility that merits exploration is that the FCE does not depend on the amount of attention received by a flanker, and that the effect of distance on the FCE is due to some factor other than a reduction in attentional allocation.

As in Experiment 1, an unusual pattern of flanker identity effects was observed, characterized mainly by slow responses when flankers were identical. Again, we have no specific explanation for this pattern, but merely emphasize that any identity-based flanker effect indicates recognition of the unattended stimuli.

\section{EXPERIMENT 7}

Our fifth hypothesis is that the FCE depends on the impoverished nature of the relevant visual display. The human visual system has evolved the capacity to analyze very complex scenes rapidly, and a great deal of parallelism is evident in its architecture (see, e.g., Cowey, 1979). It would not be too surprising if such machinery automatically analyzed as much as possible of the visual input, which might result in complete analysis of any display that seriously underloaded the perceptual system (cf. Reiner \& Morrison, 1983). Evidence of early selection in relatively complex displays (see, e.g., Neisser \& Becklen, 1975) is certainly consistent with this view.

This perceptual underload hypothesis depends to some degree on the assumption of limited-capacity perceptual processing (see, e.g., Kahneman, 1973). If perceptual processing capacity is completely unlimited (see, e.g., Shiffrin, 1976), to increase perceptual load would not detract from flanker processing.

Though the evidence on perceptual processing capacity is mixed, sufficient results have indicated processing limits to suggest that perceptual underload might be responsible for the FCE. For example, Kahneman and Chajczyk (1983) found that the Stroop effect was reduced when the display contained a color-irrelevant word in addition to the color-relevant word. Similarly, Dark, Johnston, Myles-Worsley, and Farah (1985) found that a single irrelevant word in a display produced a considerable semantic priming effect, but that two irrelevant words produced little or no effect. Both of these findings are consistent with the idea that the extent of processing for any given unattended item is influenced by the total amount of unattended material in the display. Extrapolating to the present task, one would also expect that the amount of processing of the unattended material might be reduced when there was an increase in the total relevant portion of the display, possibly eliminating the effect with a reasonably complex display.

The perceptual underload hypothesis seems to be weakened by the presence of FCEs (albeit primarily for adjacent letters) in cuing studies (e.g., C. W. Eriksen \& St. James, 1986; Yantis \& Johnston, 1990), in which eight letters are displayed around a fixation point, with a cue indicating which one is relevant. Although these studies 
demonstrate FCEs with richer visual displays, they still provide relatively few letters in the attended part of the display. In most conditions, a single letter has been cued, and it appears that no study has cued more than three letters (C. W. Eriksen \& St. James, 1986). It is easy to imagine that perceptual underload is a function of the size of the attended part of the display rather than the entire display, in which case the FCEs in these studies do not cause problems for the perceptual underload hypothesis after all, since even three letters is not a particularly large perceptual load.

To test the involvement of perceptual underload in the FCE, it seems best to provide more relevant letters as added grist for the perceptual mill. In Experiments 7-10, this was accomplished by augmenting the relevant center region of the display. Instead of a single letter, as in the standard focused attention task, the center region consisted of a number of relevant letters positioned around an imaginary circle, as shown in Figure 10. One of the relevant letters was a target, and the others were distractors. Because the position of the target around the circle was unknown in advance, it was assumed that the subject would have to perform some perceptual analysis for all of the letters on the circle (Neisser, 1963, 1967). The irrelevant flankers were letters displayed out to the edge of the circle, which were made somewhat larger than the letters on the circle to provide adequate acuity. ${ }^{12}$

Within these displays, the number of relevant letters around the circle was varied (two, four, or eight). If the perceptual underload hypothesis is correct, the FCE should decrease as the number of relevant letters increases. If the largest display is sufficiently complex, the FCE should disappear under this perceptual load. On the other hand, if perceptual underload does not contribute to the FCE, the effect should be independent of the number of relevant letters.

\section{Method}

Each of 70 subjects was tested in a single session lasting about $45 \mathrm{~min}$, with the same basic apparatus, stimuli, and procedure as in the previous experiments. The target letters were about $1.1^{\circ}$ high and $0.7^{\circ}$ wide, and their inner edges were about $1.4^{\circ}$ from fixation. The flanker letters were about $4.2^{\circ}$ high and $2.2^{\circ}$ wide, and their inner edges were about $5.4^{\circ}$ from fixation.

Each subject served in two blocks of 300 experimental trials, with 20 warm-up trials preceding the first block and four preceding the second. For each subject, two consonants were randomly selected as targets for each response, and one was randomly selected to be the neutral flanker. The other consonants were used as distractors on the central circle. Within each block, there were 5 trials with

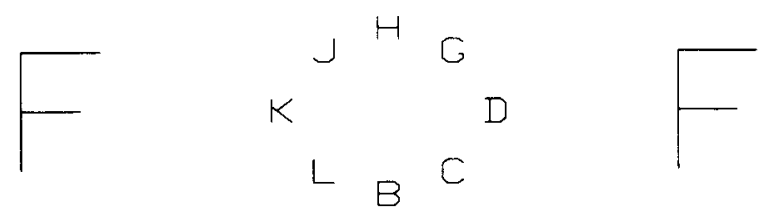

Figure 10. Stimulus arrangement used in Experiments 7-10.
Table 1

Reaction Time in Milliseconds (RT) and Percentage of Correct Responses (PC) as a Function of Display Size and Flanker Identity: Experiment 7

\begin{tabular}{|c|c|c|c|c|c|c|}
\hline \multirow[b]{3}{*}{ Flanker Identity } & \multicolumn{6}{|c|}{ Display Size } \\
\hline & \multicolumn{2}{|c|}{ Two Letters } & \multicolumn{2}{|c|}{ Four Letters } & \multicolumn{2}{|c|}{ Eight Letters } \\
\hline & RT & PC & RT & PC & RT & $\mathrm{PC}$ \\
\hline Identical & 699 & 94.8 & 867 & 94.6 & 1,049 & 94.8 \\
\hline Response-compatible & 700 & 95.1 & 861 & 95.2 & 1,059 & 94.6 \\
\hline Neutral & 704 & 94.5 & 869 & 94.5 & 1,061 & 94.6 \\
\hline Response-incompatible & 719 & 94.4 & 877 & 94.5 & 1,046 & 94.1 \\
\hline
\end{tabular}

each combination of four target letters, five flanker letters, and three display sizes (two, four, or eight letters around the central circle). Every display had exactly one target letter somewhere on the circle, with one, three, or seven other positions occupied by distractors, and assignments of targets and distractors to locations on the circle were random. All distractor letters were unique, and the neutral flanker was never used as a distractor.

Each trial began with the presentation for $500 \mathrm{msec}$ of a fixation cross at the center of the screen. About $1 \mathrm{sec}$ after the offset of the fixation cross, the display appeared, and it remained present until a response was made. Trials with responses faster than $200 \mathrm{msec}$ or slower than $3.5 \mathrm{sec}$ were discarded and rerun at a randomly selected point later in the block.

\section{Results and Discussion}

Table 1 shows averages across subjects as a function of display size and flanker identity. As display size increased, overall RT increased $[F(2,138)=689, p<$ $.001]$, and the effect of flanker identity on RT decreased $[F(6,414)=2.51, p<.025]$. Practice also had significant effects on both RT and PC.

Further analyses were conducted to examine the effect of flanker identity on RT for each display size separately. This effect was highly reliable for the display with two letters $[F(3,207)=7.19, p<.001]$, but it was not reliable for the display with four letters $[F(3,207)=1.72$, $p>.15]$ or the display with eight letters $[F(3,207)=$ $1.25, p>.25]$. Thus, the RT differences as a function of flanker type can be attributed to random variability for the larger two display sizes.

These results are fully compatible with the perceptual underload hypothesis, and they support the view that irrelevant flankers are processed only because the display is impoverished. At last, then, it seems we have found a boundary condition for the FCE, as well as a way to explain the effect in terms of a limitation on early selection.

An alternative explanation, however, is provided by the substantial change in overall RT as a function of display size. The FCE is known to be highly sensitive to the temporal relation between recognition of the target and the flankers (see, e.g., C. W. Eriksen \& Schultz, 1979); in particular, there is evidence that the effect disappears if the flankers are recognized too long before the target, as if the system can quickly purge itself of flanker identities once they are recognized. With larger display sizes, then, it is possible that flankers activated responses but that the activation dissipated before the target was found. If so, 
the disappearance of the FCE could not be interpreted as evidence that the flankers were never identified. This alternative explanation of the disappearance of the FCE with large display sizes was tested in Experiments 8-10, and the results strongly support it. In the end, we concluded that perceptual underload is therefore not a viable explanation of the FCE.

\section{EXPERIMENT 8}

One way to get around the timing problems associated with larger display sizes is to speed up target recognition by including multiple targets in the display. It is well known that search RT decreases as targets are added to a display (see, e.g., Holmgren, Juola, \& Atkinson, 1974), so it may be possible to more nearly equate overall RT across different display sizes by covarying the number of targets and the display size. This experiment was designed to implement this strategy, with single targets in displays of two and four letters, and four targets in displays of eight letters.

\section{Method}

This experiment was identical to the previous one, with the exception of the number of targets in displays with eight letters. In these displays, each of the two target letters assigned to the selected response appeared twice in the display, along with four distinct distractor letters. Sixty-two subjects were tested.

\section{Results and Discussion}

Table 2 shows averages across subjects as a function of display size and flanker identity. In the analysis of RTs, the effects of display size $[F(2,122)=224, p<.001]$ and flanker identity $[F(3,183)=9.24, p<.001]$ were reliable, but their interaction was not $[F(6,366)=0.6$, $p>.20]$. The analysis of $\mathrm{PC}$ also revealed significant main effects of display size $[F(2,122)=45, p<.001]$ and flanker identity $[F(3,183)=4.56, p<.01]$, and a nonsignificant interaction between them $[F(6,366)=$ $0.28, p>.20$ ]. Practice also had significant effects on both RT and PC.

Further analyses were conducted to examine the effect of flanker identity on RT for each display size separately. The effect on RT was reliable for two-letter displays $[F(3,183)=11.6, p<.001]$ and for eight-letter displays $[F(3,183)=3.08, p<.05]$, but it was not reliable for four-letter displays $[F(3,183)=1.66, p>.15]$. A sig-

Table 2

Reaction Time in Milliseconds (RT) and Percentage of Correct Responses (PC) as a Function of Display Size and Flanker Identity: Experiment 8

\begin{tabular}{|c|c|c|c|c|c|c|}
\hline \multirow[b]{3}{*}{ Flanker Identity } & \multicolumn{6}{|c|}{ Display Size } \\
\hline & \multicolumn{2}{|c|}{ Two Letters } & \multicolumn{2}{|c|}{ Four Letters } & \multicolumn{2}{|c|}{ Eight Letters } \\
\hline & RT & PC & RT & PC & RT & PC \\
\hline Identical & 659 & 94.9 & 834 & 93.4 & 748 & 96.9 \\
\hline Response-compatible & 655 & 95.3 & 829 & 93.5 & 739 & 97.4 \\
\hline Neutral & 656 & 95.0 & 833 & 93.5 & 740 & 96.5 \\
\hline Response-incompatible & 681 & 94.0 & 846 & 92.6 & 756 & 96.0 \\
\hline
\end{tabular}

nificant effect on PC was observed only for eight-letter displays $[F(3,183)=2.89, p<.05]$.

It seems clear that in this experiment the FCE was a function more of target detection latency than of overall perceptual load. A significant effect was obtained in the two faster conditions (two-letter displays and eight-letter displays with redundant targets) but not in the slowest condition (four-letter displays). Even if the FCE decreases when perceptual load increases (a trend in this direction is present in the comparison of two- and eight-letter displays) the effect is not eliminated.

One somewhat awkward aspect of the results is that the FCE for four-letter displays was numerically about the same as the FCE for eight-letter displays, even though it was significant only in the latter condition. Thus, it is not legitimate to conclude that the FCE differs across the two conditions, in spite of the different outcomes of the statistical test. The point is that the significant FCE with eight-letter displays damages the perceptual underload hypothesis regardless of whether or not there is an FCE with four-letter displays. If there really also is an FCE with four-letter displays (and the consistency of the fourletter-display results for Experiments 7 and 8 suggests that there is), this is simply additional evidence against the perceptual underload hypothesis.

Overall, these results support the timing explanation for the disappearance of the FCE with multiple relevant stimuli, thereby tending to vitiate the support for the perceptual underload hypothesis. Further comparisons of the two hypotheses are needed, however, because it is possible that the inclusion of multiple targets in large displays had some unanticipated effect. In particular, it might be argued that redundant targets in the display reduced the effective perceptual load below that normally associated with the large display size. This argument is tenuous even in the absence of further evidence, however, because the perceptual load would surely be greater in displays of eight letters, which had 6 different letter identities, than in displays of four letters.

\section{EXPERIMENT 9}

In Experiment 8, we sought to equate target and flanker recognition time by speeding the recognition of targets. In Experiment 9, we delayed recognition of the flankers. The most straightforward way of doing this is to delay flanker presentation until somewhat after target presentation (cf. C. W. Eriksen \& Schultz, 1979). In Experiment 9 , the single-target, eight-letter-display condition of Experiment 7 was replicated exactly, except that the flankers were delayed 250,350 , or 450 msec after presentation of the circle of letters. These times were chosen on the basis of the overall effect of display size on RT in Experiment 7.

\section{Method}

Sixty subjects were tested in a minor revision of Experiment 7. All the displays had eight relevant letters, including exactly one target letter, and the flanker onset delay was 250,350 , or 450 msec. 


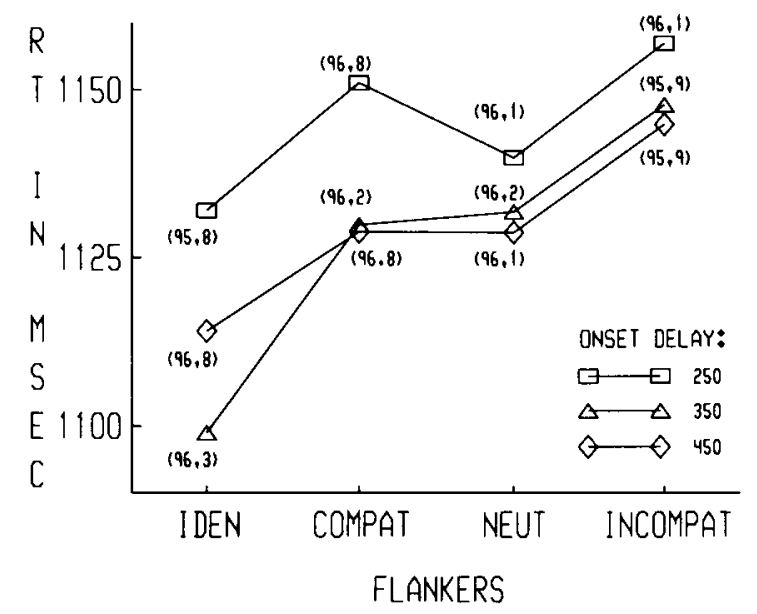

Figure 11. Experiment 9 (onset-transient flankers): Reaction time (RT) and percentage of correct responses (in parentheses) as a function of flanker identity (identical, response compatible, neutral, response incompatible) and onset delay of flankers.

\section{Results and Discussion}

Figure 11 shows average performance as a function of flanker onset delay and flanker identity. Both factors had significant effects on RT [flanker identity: $F(3,177)=$ $8.24, p<.001$; onset delay: $F(2,118)=3.82, p<$ $.025]$, but their interaction did not approach significance $[F(6,354)=0.45, p>.20]$.

These results provide further support for the timing account of the lack of FCE with large displays in Experiment 7 . The FCE can clearly be obtained with large displays, as long as flanker onset is delayed relative to the onset of the relevant portion of the display. Thus, the perceptual underload hypothesis seems untenable after all; even with fairly complex perceptual displays, unattended letters are processed semantically to some degree.

Responses were slower overall with the onset delay of $250 \mathrm{msec}$ than they were with either of the other onset delays. This suggests that the analysis of the relevant display material may have been especially vulnerable to some type of distraction by flanker onset at approximately this point in time. However, there is no evidence that the additional distractive power of the 250 -msec flankers led to their fuller semantic processing. The interaction of flanker type and SOA was not significant, and the FCE was numerically smaller with the SOA of $250 \mathrm{msec}$ than with either of the other delays.

\section{EXPERIMENT 10}

The implications of Experiment 9 could be questioned because the flankers appeared with visual onset transients noticeably after the onset of the relevant stimulus letters. The explanation in terms of transients is not particularly plausible, not only because there was no evidence that onset transients increased the FCE in Experiment 6, but also because in Experiment 9 the FCE was not largest for flankers presented with the 250 -msec delay, even though these flankers produced the greatest overall distraction decrement. Nonetheless, to eliminate onset transients as an explanation of the results of Experiment 9, Experiment 10 was a repetition of the previous one, but with offsettransient presentation of flankers as in Experiment 6.

\section{Method}

Forty-eight subjects were tested as in Experiment 9. The procedural difference was that flankers were presented by removing lines from a premask shaped like a figure 8 , as in the offset conditions of Experiment 6 . This required that the targets and neutral letter be selected from the restricted set of letters used in Experiment 6 .

\section{Results and Discussion}

Figure 12 shows average performance as a function of flanker onset delay and flanker identity. Flanker identity had a significant effect on RT $[F(3,141)=2.74, p<$ $.05]$, but onset delay did not $[F(2,94)=1.6, p>.20]$. The interaction did not approach significance $[F(6,282)$ $=1.1, p>.20]$.

Although the overall effect was significant and the interaction shown in Figure 12 was not, the effect of flanker identity seems somewhat less consistent in Experiment 10 than it was in Experiment 9, perhaps because of the smaller number of subjects. Furthermore, response-incompatible flankers did not produce the slowest responses overall, contrary to what occurred in most of the previous experiments. One possible explanation for the inconsistent and unusual effects might be based on the idea that offsettransient flankers capture less attention than onset-transient flankers, since statistical analysis indicated that subjects were over $100 \mathrm{msec}$ slower overall in Experiment 9 than in Experiment $10[F(1,106)=13, p<.01]$. This explanation is implausible, however, because flanker transients did not influence the FCE in Experiment 6.

Another possible explanation for the weakness of the flanker effects is that the use of offset-transient flankers

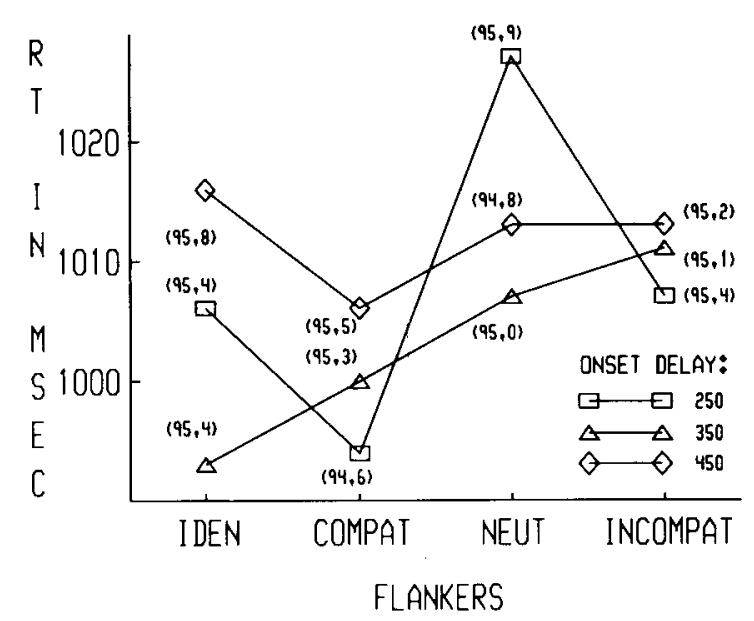

Figure 12. Experiment 10 (offset-transient flankers): Reaction time (RT) and percentage of correct responses (in parentheses) as a function of flanker identity (identical, response compatible, neutral, response incompatible) and onset delay of flankers. 
may have interacted with flanker delay to lengthen the effective interval between target and flanker recognition, thereby modifying the effect of flanker identity. It should also be noted that, across trials, there is comparatively high variance in the times at which targets are recognized, due to the nature of visual search through multi-item displays (see, e.g., Schneider \& Shiffrin, 1977). It is difficult to say how such variance would interact with flanker effects without a more precise model of these effects. Nonetheless, the existence of an identity-dependent flanker effect does indicate that the flankers were processed for meaning, so early selection was not completely effective in blocking them from semantic analysis.

The overall results of Experiments 7-10 do not support the perceptual underload hypothesis, and it is reasonable to conclude that the FCE is not entirely attributable to the highly impoverished nature of the stimulus displays used in the linear displays task. Although it was possible to eliminate the FCE by increasing the perceptual load of the relevant portion of the display, it seems clear that the decrease was really a result of delaying the response to the target rather than of inhibiting the processing of unattended flankers. It could be argued, of course, that even the largest display size used in these studies did not produce sufficient perceptual load to prevent processing of unattended stimuli. Clearly, this alternative explanation can never be dismissed completely, because it could be applied to any experiment in which the FCE was not eliminated, regardless of how many relevant items were included in the display. Given the plausibility of a much larger perceptual load with eight-item displays, however, it seems fair to conclude that the perceptual underload hypothesis is unlikely in light of these data.

The results of Experiments 7-10 do suggest that it is necessary to distinguish carefully among the effects produced by different types of flankers, because these effects may have rather different time courses. For example, responses to identical flankers had about the same speed as did responses to response-compatible flankers in Experiments 7, 8, and 10, but they were much faster in Experiment 9 . The most likely explanation for the changing results in this condition is that there was a change in the relative recognition times for flankers and relevant letters.

As discussed in the introduction, Harms and Bundesen (1983) considered the hypothesis that the FCE depends on the flankers' being perceived as part of a unitary group with the targets. They rejected this explanation, because they found that target/flanker color differences did not reduce the size of the effect. The results of Experiments 7-10 provide further evidence against this hypothesis as a complete account of the processing of unattended flankers in the focused attention task. In these experiments, the relevant items formed a nicely grouped circle at the center of the display, and the irrelevant flankers were clearly different perceptual objects because they were different in size and distance from the perceptual whole defined by the relevant circle (see Figure 10). Nonetheless, the FCE was obtained with these stimuli.

\section{GENERAL DISCUSSION}

In the present experiments, five factors have been examined that might have been responsible for the processing of unattended stimuli demonstrated by the FCE: (1) poor spatial resolution of attentional focus (strong distance hypothesis), (2) inability to hold attentional focus on a fixed location, (3) inability to focus completely on an empty display location (necessary object hypothesis), (4) inability to filter out onset-transient stimuli, and (5) inability to prevent analysis of all stimuli in an impoverished visual field (perceptual underload hypothesis).

Experiments 1 and 2 demonstrated that some form of the FCE can be obtained even with almost $5^{\circ}$ of visual angle separating the flankers from the target. Thus, poor spatial resolution of the attentional focus cannot be the sole cause of the FCE. Increasing visual angle changed the size and, in Experiment 1, the nature of the effect, either directly or by changing the relative time course of target and flanker identification (C. W. Eriksen \& Schultz, 1979; Flowers \& Wilcox, 1982). In any case, the existence of any effect in these experiments shows that unattended stimuli are sometimes processed even when they are located several degrees from attended stimuli.

Experiment 3 showed that the FCE is not eliminated when the relevant location is varied from trial to trial rather than held constant across a block of trials. Thus, the FCE cannot be attributed to difficulty in holding attentional focus on a constant location. This finding is somewhat inconsistent with previous evidence that attention can be focused better when the spatial locus varies from trial to trial (e.g., Posner, Snyder, \& Davidson, 1980), but the paradigmatic differences are so large that the difference in results is not too surprising.

Experiments 4 and 5 showed that the FCE is not abolished by giving the subject a rapidly changing display at the attended location, even though this display should provide an absorbing perceptual task. Thus, there is no evidence that the FCE is normally due to the absence of an informative visual object on which to focus attention at the relevant spatial location.

Experiment 6 yielded no evidence that the FCE depends on visual transients. In spite of the clear overall effects of transients, the FCE was independent of the type of transients in both targets and flankers. Clearly, there is no suggestion that the obligatory semantic processing of flankers is simply induced by the onset transients of the flankers. Furthermore, assuming that the type of transients influences the amount of attention paid to the flankers, this finding is evidence that the FCE is independent of the attention paid to the flankers.

In Experiments 7-10, the perceptual underload hypothesis was tested. According to this hypothesis, unattended stimuli are processed only in a highly impoverished visual field, because of a tendency to allocate spare resources to irrelevant display items. Although it is possible to eliminate the FCE by providing more attended stimuli (Experiment 7), this seems to be related more to the tem- 
poral specificity of the FCE than to a reduction in processing of unattended stimuli. Even with many attended stimuli, the FCE could be reinstated by speeding target detection within the set of relevant stimuli (Experiment 8) or by delaying flanker onset (Experiments 9 and 10).

In summary, none of the five factors examined here was capable of eliminating the FCE. Along with the results of Harms and Bundesen (1983) and Miller (1987), the evidence suggests that complete elimination of unattended stimuli from semantic processing is a rare occurrence, probably requiring a very special combination of circumstances. It appears that attenuation of unattended stimuli is generally incomplete.

The present results suggest, though they do not require, the view that early mechanisms of selection are just not designed to eliminate stimuli from all further processing. Fortunately, as long as the early selective mechanism can modulate signal strength enough for the appropriate stimuli to control behavior, unattended stimuli need not be eliminated entirely. Indeed, given the massive parallelism of the visual system, such a strategy would probably be unnecessarily wasteful of information that could potentially be useful (e.g., for controlling switches of attention, as suggested by Lambert, Beard, \& Thompson, 1988). This view casts a new light on the traditional suggestion that attentional selection is needed to protect a limited-capacity decision-making apparatus from the massive information overload provided by our stimulus world (e.g., Broadbent, 1958). The residual semantic processing of unattended stimuli suggests that even if the selection mechanism is early, the limited capacity bottleneck is rather late (see, e.g., Duncan, 1980).

It is, of course, still possible that unattended stimuli would be completely blocked from semantic analysis under some combinations of the conditions tested here, or under some other set of conditions entirely. The present experiments do not rule this out, because factors were varied one at a time and, of course, only a finite set of conditions was examined. Yantis and Johnston (1990) have apparently come the closest to constructing the optimal conditions for complete early attenuation of unattended stimuli. In their third and fourth experiments, they set up conditions with (1) highly valid location precues and time to use them; (2) active reallocation of attention, trial by trial; (3) adequate perceptual load; (4) circular displays to eliminate lateral interference favoring the flankers; and (5) adequate spacing between letters. In these experiments, impressively small FCEs were obtained, and they suggested that "earlier failures of effective spatial selection may be attributed to suboptimal conditions for eliciting such selection" (p. 146). Unfortunately, neither their own work nor the results of the present experiments make it clear just what suboptimal conditions are responsible for failures of early selection. Moreover, even an impressively small FCE is evidence that early selection was not completely successful.

Besides indicating that it is no simple matter to make selection mechanisms eliminate unattended stimuli from any semantic processing, the present results indicate that several factors have little or no effect on the extent of that processing. These factors include the constant or varied locus of attention, the presence or absence of onset transients in the target, the presence or absence of onset transients in the flankers, and the amount of relevant material in the display. In conjunction with the dependence of the FCE on target/flanker separation, these results reinforce the view that spatial location is a very special factor in the control of attention (see, e.g., Hoffman, 1986; Tsal \& Lavie, 1988), having much greater impact than other factors on the extent of processing of unattended stimuli.

In several of the present experiments, flanker identity had effects somewhat different from those most often observed, the common pattern being large inhibition for response-incompatible flankers, with possibly a small facilitation for identical and response-compatible flankers. Although any identity-based flanker effect is sufficient to demonstrate semantic processing of unattended material (i.e., failure of selective attention), the nature of the semantic processing and its effects are also worth examining. Unfortunately, it is difficult to separate facilitation and inhibition unambiguously, because of difficulty in identifying a pure neutral condition (Jonides \& Mack, 1984). Nonetheless, further studies in which the time course of flanker and target presentation is manipulated may enable us to determine the reasons for the observed changes in effects. More importantly, though, further studies of boundary conditions for the FCE should certainly include as many different types of flankers as possible. In several of the present experiments, the results would have suggested true early selection had the least commonly studied flanker type-response-compatiblebeen omitted from the design.

\section{REFERENCES}

Allport, D. A., Tipper, S. P., \& Chmiel, N. R. J. (1985). Perceptual integration and postcategorical filtering. In M. I. Posner \& O. S. M. Marin (Eds.), Mechanisms of attention: Attention \& performance $X I$ (pp. 107-132). Hillsdale, NJ: Erlbaum.

Becklen, R. Cervone, D. (1983). Selective looking and the noticing of unexpected events. Memory \& Cognition, 11, 601-608.

Bonnel, A. M., Possamai, C. A., a Schmitt, M. (1987). Early modulation of visual input: A study of attentional strategies. Quarterly Journal of Experimental Psychology: Section A. Human Experimental Psychology, 39, 757-776.

Breitmeyer, B. G., \&ANZ, L. (1976). Implications of sustained and transient channels for theories of visual pattern masking, saccadic suppression, and information processing. Psychological Review, 83, 1-36.

Brondbent, D. E. (1958). Perception and communication. London: Pergamon.

Brondbent, D. E. (1982). Task combination and selective intake of information. Acta Psychologica, 50, 253-290.

CoweY, A. (1979). Cortical maps and visual perception: The Grindley Memorial Lecture. Quarterly Journal of Experimental Psychology, 31, 1-17.

Dark, V. J., Johnston, W. A., Myles-Worsley, M., \& Farah, M. J. (1985). Levels of selection and capacity limits. Joumal of Experimental Psychology: General, 114, 472-497.

Deutsch, J. A., \& Deutsch, D. (1963). Attention: Some theoretical considerations. Psychological Review, 70, 80-90.

Driver, J., BAYLIS, G. C. (1989). Movement and visual attention: The spotlight metaphor breaks down. Journal of Experimental Psychology: Human Perception \& Performance, 15, 448-456. 
Duncan, J. (1980). The locus of interference in the perception of simultaneous stimuli. Psychological Review, 87, 272-300.

Duncan, J. (1981). Directing attention in the visual field. Perception \& Psychophysics, 30, 90-93.

DUNCAN, J. (1984). Selective attention and the organization of visual information. Journal of Experimental Psychology: General, 113, 501-517.

EGETH, H. E. (1977). Attention and preattention. In G. H. Bower (Ed.), The psychology of leaming and motivation (Vol. 11, pp. 277-320). New York: Academic Press.

ERIKSEN, B. A., ERIKSEN, C. W. (1974). Effects of noise letters upon the identification of a target letter in a nonsearch task. Perception \& Psychophysics, 16, 143-149.

ERIKSEN, C. W., \& Hoffman, J. E. (1972a). Some characteristics of selective attention in visual perception determined by vocal reaction time. Perception \& Psychophysics, 11, 169-171.

ERIKSEN, C. W., \& Hoffman, J. E. (1972b). Temporal and spatial characteristics of selective encoding from visual displays. Perception \& Psychophysics, 12, 201-204.

ERIXsen, C. W., Hoffman, J. E. (1973). The extent of processing of noise elements during selective encoding from visual displays. Perception \& Psychophysics, 14, 155-160.

ERIKSEN, C. W., SChultz, D. W. (1979). Information processing in visual search: A continuous flow conception and experimental results. Perception \& Psychophysics, 25, 249-263.

ERIKSEN, C. W., \& ST. JAmES, J. D. (1986). Visual attention within and around the field of focal attention: A zoom lens model. Perception \& Psychophysics, 40, 225-240.

FLoWERS, J. H., WiLcox, N. (1982). The effect of flanking context on visual classification: The joint contribution of interactions at different processing levels. Perception \& Psychophysics, 32, 581-591.

Francolini, C. M., \& Egeth, H. E. (1980). On the nonautomaticity of "automatic" activation: Evidence of selective seeing. Perception \& Psychophysics, 27, 331-342.

GAThercole, S. E., Brondbent, D. E. (1987). Spatial factors in visual attention: Some compensatory effects of location and time of arrival of nontargets. Perception, 16, 433-443.

GATTI, S. V., EGETH, H. E. (1978). Failure of spatial selectivity in vision. Bulletin of the Psychonomic Society, 11, 181-184.

HagenaAR, R., VAN DER Heijden, A. H. C. (1986). Target-noise separation in visual selective attention. Acta Psychologica, 62, 161-176.

HARMs, L., Bundesen, C. (1983). Color segregation and selective attention in a nonsearch task. Perception \& Psychophysics, 33, 11-19.

Hillyard, S. A., Munte, T. F., Neville, H. J. (1985). Visualspatial attention, orienting, and brain physiology. In M. I. Posner \& O. S. M. Marin (Eds.), Mechanisms of attention: Attention \& performance $X I$ (pp. 63-84). Hillsdale, NJ: Erlbaum.

Hoffman, J. E. (1986). Spatial attention in vision. Psychological Research, 48, 221-229.

Hoffman, J. E., Nelson, B., Houck, M. R. (1983). The role of attentional resources in automatic detection. Cognitive Psychology, $15,379-410$.

Holmgren, J. E., Juola, J. F., \& Atinsson, R. C. (1974). Response latency in visual search with redundancy in the visual display. Perception \& Psychophysics, 16, 123-128.

Humphreys, G. W. (1981). Flexibility of attention between stimulus dimensions. Perception \& Psychophysics, 30, 291-302.

Johnston, W. A., DARK, V. J. (1982). In defense of intraperceptual theories of attention. Journal of Experimental Psychology: Human Perception \& Performance, 8, 407-421.

Johnston, W. A., \& DARK, V. J. (1986). Selective attention. Annual Review of Psychology, 37, 43-75.

Johnston, W. A., Heinz, S. (1978). Flexibility and capacity demands of attention. Journal of Experimental Psychology: General, $107,420-435$.

JONIDES, J. (1981). Voluntary versus automatic control over the mind's eye's movement. In J. B. Long \& A. D. Baddeley (Eds.), Attention and performance (Vol. 9, pp. 187-203). Hillsdale, NJ: Erlbaum.

JoNides, J., \& MACK, R. (1984). On the cost and benefit of cost and benefit. Psychological Bulletin, 96, 29-44.

JoNIDES, J., \& YANTIS, S. (1988). Uniqueness of abrupt visual onset in capturing attention. Perception \& Psychophysics, 43, 346-354.
Kahneman, D. (1973). Attention and effort. Englewood Cliffs, NJ: Prentice-Hall.

Kahneman, D., \& Chajczyk, D. (1983). Tests of the automaticity of reading: Dilution of Stroop effects by color-irrelevant stimuli. Journal of Experimental Psychology: Human Perception \& Performance. 9. 497-509.

Kahneman, D., Henik, A. (1981). Perceptual organization and attention. In M. Kubovy \& J. R. Pomerantz (Eds.), Perceptual organization (pp. 181-211). Hillsdale, NJ: Erlbaum.

Kahneman, D., \& Treisman, A. M. (1984). Changing views of attention and automaticity. In R. Parasuraman \& D. R. Davies (Eds.), Varieties of attention (pp. 29-61). New York: Academic Press.

LABERGE, D. (1983). Spatial extent of attention to letters and words. Journal of Experimental Psychology: Human Perception \& Performance, 9, 371-379.

LAMBERT, A. J. (1985). Selectivity and stages of processing: An enduring controversy in attentional theory: A review. Current Psychological Research \& Reviews, 4, 239-256.

LAMBert, A. J., BeARD, C. T., Thompson, R. J. (1988). Selective attention, visual laterality, awareness, and perceiving the meaning of parafoveally presented words. Quarterly Joumal of Experimental Psychology: Section A. Human Experimental Psychology, 40, 615-652.

LitTMAN, D., BECKLEN, R. (1976). Selective looking with minimal eye movements. Perception \& Psychophysics, 20, 77-79.

MerikLe, P. M., Gorewich, N. J. (1979). Spatial selectivity in vision: Field size depends upon noise size. Bulletin of the Psychonomic Society, 14, 343-346.

Miller, J. (1987). Priming is not necessary for selective-attention failures: Semantic effects of unattended, unprimed letters. Perception \& Psychophysics, 41, 419-434.

Miller, J. (1988). Response-compatibility effects in focused-attention tasks: A same-hand advantage in response activation. Perception \& Psychophysics, 43, 83-89.

MiLler, J. (1989). The control of attention by abrupt visual onsets and offsets. Perception \& Psychophysics, 45, 567-571.

Murphy, T. D., ERIKSEN, C. W. (1987). Temporal changes in the distribution of attention in the visual field in response to precues. Perception \& Psychophysics, 42, 576-586.

NeISSER, U. (1963). Decision time without reaction time: Experiments in visual scanning. American Joumal of Psychology, 76, 376-385.

NeIsser, U. (1967). Cognitive psychology. New York: AppletonCentury-Crofts.

NeIsser, U. (1979). The control of information pickup in selective looking. In A. D. Pick (Ed.), Perception and its development: A tribute to Eleanor J. Gibson (pp. 201-219). Hillsdale, NJ: Erlbaum.

Neisser, U., Becklen, R. (1975). Selective looking: Attending to visually specified events. Cognitive Psychology, 7, 480-494.

PoSNER, M. I. (1980). Orienting of attention. Quarterly Journal of Experimental Psychology, 32, 3-25.

Posner, M. I., CoHEN, Y. (1984). Components of visual orienting In H. Bouma \& D. G. Bowhuis (Eds.), Attention and performance. Vol. 10. Control of language processes (pp. 531-556). Hillsdale, NJ: Erlbaum.

Posner, M. I., Cohen, Y., Chonte, L. S., Hockey, R. J., \& MayLOR, E. (1984). Sustained concentration: Passive filtering or active orienting? In S. Kornblum \& J. Requin (Eds.), Preparatory states and processes (pp. 49-65). Hillsdale, NJ: Erlbaum.

Posner, M. I., SNYDer, C., DAvidson, B. (1980). Attention and the detection of signals. Journal of Experimental Psychology: General, $109,160-174$.

Reiner, M. B., Morrison, F. J. (1983). Is semantic interference really automatic? Bulletin of the Psychonomic Society, 21, 271-274.

SChNeider, W., Shiffrin, R. M. (1977). Controlled and automatic human information processing: I. Detection, search, and attention. Psychological Review, 84, 1-66.

SHIFFrin, R. M. (1976). Capacity limitations in information processing, attention, and memory. In W. K. Estes (Ed.), Handbook of learming and cognitive processes (Vol. 4, pp. 177-236). Hillsdale, NJ: Erlbaum.

Skelton, J. M., ERIKSEN, C. W. (1976). Spatial characteristics of selective attention in letter matching. Bulletin of the Psychonomic Society, 7, 136-138. 
SPEnCER, M. B. H., LAmbert, A. J., \& Hockey, R. (1988). The inhibitory component of orienting, alertness and sustained attention. Acta Psychologica, 69, 165-184.

STROOP, J. R. (1935). Studies of interference in serial verbal reactions. Joumal of Experimental Psychology, 18, 643-662.

Treisman, A. M. (1964). Selective attention in man. British Medical Bulletin, 20, 12-16.

Treisman, A. [M]., Kahneman, D., \& Burkell, J. (1983). Perceptual objects and the cost of filtering. Perception \& Psychophysics, $33,527-532$.

TSAL, Y., \& LAVIE, N. (1988). Attending to color and shape: The special role of location in selective visual processing. Perception \& Psychophysics, 44, 15-21.

UMILTA, C. (1988). Orienting of attention. In F. Boller \& J. Grafman (Eds.), Handbook of neuropsychology (Vol. 1, pp. 175-193). Amsterdam: Elsevier

VAN DER HeIJden, A. H. C. (1981). Short-term visual information forgetting. London: Routledge \& Kegan Paul.

Yantis, S., Johnston, J. C. (1990). On the locus of visual selection: Evidence from focused attention tasks. Journal of Experimental Psychology: Human Perception \& Performance, 16, 135-149.

YANTIS, S., \& JonidES, J. (1984). Abrupt visual onsets and selective attention: Evidence from visual search. Joumal of Experimental Psychology: Human Perception \& Performance, 10, 601-621.

YANTIS, S., \& JoNIDES, J. (1990). Abrupt visual onsets and selective attention: Voluntary versus automatic allocation. Journal of Experimental Psychology: Human Perception \& Performance, 16, 121-134.

\section{NOTES}

1. We regard Neisser's (1979) information pickup theory as a variant of early filter theory, because it denies semantic processing of unselected information.

2. Similar displays were also used in earlier studies by $C$. W. Eriksen and Hoffman (e.g., 1972a, 1972b), but these studies did not evaluate the FCE as defined here.

3. Humphreys (1981), on the other hand, did find evidence that target/noise color differences facilitate perceptual selection, but in a very different paradigm. One important difference may have been that the stimuli in Humphreys's experiments were left- and right-facing parentheses, with subjects making a direction judgment with respect to the relevant one. This appears to be a more perceptual and less semantic task than letter classification, so it is not surprising that perceptual variables would have a greater effect with these stimuli than with letters.

4. Actually, there are hints of FCEs for flankers in locations directly across the circle from the relevant one (e.g., Yantis \& Johnston, 1990, Experiment 3; cf. Duncan, 1984; Skelton \& C. W. Eriksen, 1976), contrary to the strong distance hypothesis.

5. They did not report a statistical test of this specific FCE, so we cannot be sure that it was statistically reliable. Even if it was not, however, the presence of the effect in the means causes problems for the strong distance hypothesis, according to which it should be virtually absent in this condition.

6. I am indebted to C. W. Eriksen for pointing this out

7. The comparison of different patterns of semantic effects as a function of separation is statistically justified. In an overall analysis of RT that included both separations, the interaction shown in Figure 1 was highly reliable $[F(3,105)=9.08, p<.001]$.

8. Of course this reintroduces the potential confound that the flankers may attract attention by virtue of being larger than the target. It does not appear that target size, flanker/target-size ratio, and flanker acuity can all be independently controlled with this type of display.

9. It is unusual to conduct separate flanker effect tests for each frame, given that the frame $x$ flanker interaction was not significant, but scientific logic justifies the analyses in this case. The necessary object hypothesis implies both that there should have been an interaction and that the only main effect should have occurred in the first frame. It is legitimate to show that this hypothesis fails not only with respect to the overall interaction but also with respect to the presence of individual main effects. If anything, the individual main effect tests are better evidence against the hypothesis, because they do not involve the statistical miasma of "accepting the null hypothesis" as does the nonsignificant interaction.

10. A further analysis was conducted, in which only responsecompatible and response-incompatible flankers were included. This analysis is potentially more powerful, because it concentrates the flanker identity $x$ transients interactions in the most extreme identity conditions. Again, none of the three interactions approached significance.

11. One aspect of the data is not predicted by the hypothesis that subjects allocate more attention to onset transients; the slowest condition overall is the one with onset-transient targets and flankers. Assuming that onset transients grab attention, subjects should be slowest with onsettransient flankers and offset-transient targets, because in that condition attention would be most strongly misdirected to the flankers. Slight fixation differences may be responsible for this discrepancy. In the condition with both onsets, the display was blank for $500 \mathrm{msec}$ before stimulus onset, whereas in all the other conditions, there were visual cues to the center of the upcoming display. Overall RT might be increased if fixation were to wander slightly off center in the condition with both onsets.

12. Unfortunately, it was not possible for relevant letters to have the same size as that of the irrelevant letters, because there was simply not enough room on our displays. For now, we will have to acknowledge the possibility of a size confound: These flankers may have received some attention because they were the largest items in the visual field.

(Manuscript received July 11, 1988; revision accepted for publication September 10, 1990.) 